\title{
Intestinal Recruitment of CCR6-Expressing Th17 Cells By Suppressing miR-681 Alleviates Endotoxemia-Induced Intestinal Injury And Reduces Mortality
}

\author{
Liwen Gu \\ Sun Yat-Sen University \\ Jie Jiang \\ Sun Yat-Sen University \\ Zhigang Liu \\ Sun Yat-Sen University \\ Qiangqiang Liu \\ Sun Yat-Sen University \\ Jinli Liao \\ Sun Yat-Sen University
}

Qingli Zeng

Sun Yat-Sen University

Chuanxi Chen

Sun Yat-Sen University

Zhihao Liu ( $\square$ liuzhhao@mail2.sysu.edu.cn )

Sun Yat-Sen University https://orcid.org/0000-0002-0047-8990

\section{Research}

Keywords: miRNAs, Th17 cells, endotoxemia, intestinal injury

Posted Date: December 15th, 2021

DOI: https://doi.org/10.21203/rs.3.rs-1096352/v1

License: (9) This work is licensed under a Creative Commons Attribution 4.0 International License. Read Full License 


\section{Abstract}

\section{Background}

Sepsis or endotoxemia can induce intestinal dysfunction in the epithelial and immune barrier. Th17 cells, a distinct subset of CD4 ${ }^{+}$T-helper cells, act as "border patrol" in the intestine under pathological condition and in the previous studies, Th17 cells exhibited an ambiguous function in intestinal inflammation. Our study will explore a specific role of Th17 cells and its relevant mechanism in endotoxemia-induced intestinal injury.

\section{Methods}

Lipopolysaccharide was used to establish mouse model of endotoxemia. miR-681 was analyzed by RTPCR and northern blot analysis and its regulation by HIF-1a was determined by chromatin immunoprecipitation and luciferase reporter assay. Intestinal Th17 cells isolated from endotoxemic mice were quantitatively evaluated by flow cytometry and its recruitment to the intestine controlled by miR681/CCR6 pathway was assessed by using anti-miRNA treatment and CCR6 knockout mice. Intestinal histopathology, villus length, intestinal inflammation, intestinal permeability, bacterial translocation and survival were investigated, by histology and TUNEL analysis, ELISA, measurement of diamine oxidase, bacterial culture, with or without anti-miR-681 treatment in endotoxemic wild-type and (or) CCR6 knockout mice.

\section{Results}

In this study, we found that miR-681 was significantly promoted in intestinal Th17 cells during endotoxemia, which was dependent on hypoxia-inducible factor-1a (HIF-1a). Interestingly, miR-681 could directly suppress CCR6, which was a critical modulator for Th17 cell recruitment to the intestines. In vivo, anti-miR-681 enhanced survival, increased number of intestinal Th17 cells, reduced crypt and villi apoptosis, decreased intestinal inflammation and bacterial translocation, resulting in protection against endotoxemia-induced intestinal injury in mice. However, CCR6 deficiency could neutralize the beneficial effect of anti-miR-681 on the intestine during endotoxemia, suggesting that the increment of intestinal Th17 cells caused by anti-miR-681 relies on CCR6 expression.

\section{Conclusion}

The results of the study indicate that control of intestinal Th17 cells by regulating novel miR-681/CCR6 signaling attenuates endotoxemia-induced intestinal injury.

\section{Introduction}

Sepsis or endotoxemia is characterized by elevated levels of lipopolysaccharide (LPS) in the blood and is mostly caused by Gram-negative bacteria. Sepsis remains a leading cause of death in critically ill patients ${ }^{1}$. Sepsis-induced intestinal injury is believed to have a crucial impact on the pathophysiology of 
sepsis by fueling the unremitting inflammatory responses both locally and systematically ${ }^{2,3,4}$. Sepsis induces several aberrations in the intestinal epithelium, including epithelial barrier dysfunction ${ }^{5,6}$, increased epithelial apoptosis ${ }^{7,8}$, and production of numerous inflammatory factors ${ }^{9,10}$. The intestinal mucosal surface is a large anatomical barrier through which different pathogenic bacteria, fungi, viruses, or parasites can potentially invade and harm the host. Therefore, immune cells in the intestine are essential in maintaining the epithelial barrier, suppressing excessive intestinal inflammation, and restraining pathogens from invading.

Interleukin (IL)-17-producing CD $4^{+}$T-helper cells (Th17), a newly distinct subset of $\mathrm{CD} 4^{+} \mathrm{T}$ cells, are commonly associated with chronic inflammation and autoimmune diseases ${ }^{11}$. Previous studies have shown that Th17 cells are defined as RORyt-expressing $C D 4^{+} T C R \beta^{+} T$ cells and function as a "border patrol" in the intestine ${ }^{12,13}$. Th17 cells are also believed to possess a variety of pro-inflammatory functions as they defend mucosal barriers. It has been demonstrated that the number of intestinal Th17 cells is associated with intestinal inflammation in inflammatory bowel disease ${ }^{14}$ and that the adoptive transfer of in vitro or in vivo differentiated Th17 cells into lymphopenic mice induces the development of colitis $^{15,16,17,18}$. Moreover, the enhanced differentiation of Th17 cells in DUSP2-deficient mice resulted in increased intestinal inflammation and susceptibility to experimental colitis ${ }^{19}$. On the contrary, other studies have indicated that intestinal Th17 cells can acquire immunosuppressive functions, which protect against intestinal inflammation. IL-17 and IL-22 secreted by Th17 cells in the intestine have been reported to diminish dextran sulfate sodium-induced colitis and $C$. rodentium-induced intestinal epithelial damage, respectively $20,21,22$. Furthermore, in a Th17 cell-mediated colitis model, Th17 cells with regulatory functions prevented Th17 cell-mediated colitis ${ }^{23}$, highlighting that Th17 cells can have both pathogenic and beneficial effects in intestinal inflammation.

MicroRNAs (miRNAs) are a class of noncoding RNA molecules 21-23 nucleotides in length. They are endogenously expressed and have partial sequence homology to the $3^{\prime}$-untranslated region (UTR) of specific messenger RNAs (mRNAs), negatively regulating translation of the target mRNA to protein ${ }^{24}$. Previous studies have shown that miRNAs play crucial roles in many aspects of cellular physiology and have been implicated in pathological processes in the intestine, such as intestinal inflammation, intestinal permeability, and gut barrier dysfunction. For instance, miR-301A, miR-223, miR-214, miR68155, and miR-68124 have been found to modulate intestinal inflammation ${ }^{25,26,27}$, while miR-21-5p and miR-68122a could increase intestinal epithelial permeability leading to bacterial invasion ${ }^{27,28}$. The miRNAs miR-21, miR-68150, and miR-68146 have been shown to modulate intestinal epithelial homeostasis by regulating cell apoptosis and cell-to-cell interactions ${ }^{27}$. However, the function and implication of miRNAs in intestinal mucosal immune cells in the context of endotoxemia-induced intestinal injury remains poorly understood.

In this study, we identified ten miRNAs, the expression of which was altered in intestinal Th17 cells during endotoxemia. Moreover, we identified miR-681 to be markedly induced in intestinal Th17 cells, targeting 
chemokine receptor 4 (CCR6). Blocking miR-681 facilitated the recruitment of Th17 cells to the intestine and mitigated intestinal injury in response to endotoxemia.

\section{Materials And Methods}

\section{Animals, experimental endotoxemia, and anti-miRNA treatment}

All experiments involving animals were approved by the Animal Care and Use Committee of the Sun Yatsen University, Guangzhou, China (approval number: 2018007). CCR6 wild-type (WT) and knockout (KO) C57BL/6 male mice were purchased from the Model Animal Research Center of Nanjing University (Nanjing, China). Experimental endotoxemia was induced in 6-week-old mice by intravenous administration of lipopolysaccharide (LPS) from Escherichiacoli (17.5 mg/kg, 055:B5; Sigma-Aldrich, St. Louis, MO, USA); $350 \mu \mathrm{g}$ LPS in $100 \mu \mathrm{L}$ of saline was injected. Sepsis was induced by the administration of $E$. coli ( $10^{9}$ colony forming units [CFU]/per mouse; ATCC). Mice were observed every $4 \mathrm{~h}$ during the critical stages of the disease, and euthanized with chloral hydrate at predefined endpoints: breathing rate less than 120 breaths per minute, loss of circulation to the tails or feet, or loss of responsiveness to stimuli. Surviving mice were monitored closely for 5 days and euthanized 10 days after injection of LPS. Small intestines were harvested for further analyses 3 days after injection with LPS.

Anti-miRNA treatment was performed as previously described ${ }^{30}$. Anti-miR-681 oligonucleotide and scrambled negative control (Ambion, Austin, TX, USA) were diluted in invivo-jetPEl solution (Polyplustransfection) containing $10 \%(\mathrm{wt} / \mathrm{vol})$ glucose at a ratio of invivo-jetPEI nitrogen residues per oligonucleotide phosphate of 5 , according to the manufacturer's instructions. Solutions were incubated for $20 \mathrm{~min}$ at $37^{\circ} \mathrm{C}$ before injection. Each mouse was administered $400 \mu \mathrm{L}$ of a saline and oligonucleotide mixture (corresponding to $300 \mu \mathrm{g}$ of oligonucleotide per dose) daily through tail vein injection for at least 3 days before LPS injection, and continuously for 1-3 days or 5 days after LPS injection. Small intestines were harvested $72 \mathrm{~h}$ after the last LPS injection.

\section{Histology, double immunofluorescence staining, and TUNEL analysis}

Sections ( $3 \mu \mathrm{m}$ thick) from paraffin-embedded intestinal bundles (jejunum) were subjected to hematoxylin and eosin (H\&E) staining for histological analysis. For double immunofluorescence staining, immunofluorescence of IL-17 and fluorescence in situ hybridization (FISH) analysis for miR-681 were performed. Briefly, jejuna were harvested to prepare 10- $\mu \mathrm{m}$ frozen sections. Sections were incubated with anti-IL-17 antibody (Abcam, England)at 1:100 dilution overnight at $4{ }^{\circ} \mathrm{C}$, followed by incubation with the fluorescent secondary antibody streptavidin Alexa 488 (Invitrogen, Carlsbad, CA, USA) and counterstain with DAPI (Invitrogen). Subsequently, the sections were hybridized with 5' fluorescein-labeled miR-681 LNA probe or scrambled sequence LNA probe (Exiqon, USA). The hybridization signal was amplified using the tyramide signal amplification system (PerkinElmer, Waltham, MA, USA). Fluorescent images were acquired using the Leica DMI3000B microscope (Leica, Wetzlar, Germany). 
TUNEL staining was performed using an in situ cell death detection kit (Roche, Basel, Switzerland), according to the manufacturer's instructions. The apoptotic index was assessed in full longitudinal sections of villi and intact crypts containing at least 14 cells, including Paneth cells. The average frequencies of apoptosis for villi and crypts were determined in 50 and 100 villi-crypt sections, respectively. Apoptotic index scores are presented as mean \pm standard deviation (SD). Three independent observers, blinded to the genotype and treatment, performed the apoptotic index scoring.

\section{Intestinal mucosal scraping and ELISA assays}

Jejuna were opened longitudinally on the antimesenteric border to expose the intestinal mucosa. The mucosal layers were harvested by gently scraping with a glass slide for further investigation.

The concentrations of tumor necrosis factor (TNF)- $a$, IL-6, and IL-10 in the small intestinal mucosa of mice were determined using a commercial ELISA kit (eBioscience, San Diego, CA, USA), according to the manufacturer's instructions. After incubating with the stop solution, the optical absorbance at $450 \mathrm{~nm}$ (570 nm correction) was read on a Microplate Reader (BioTek, Seattle, WA, USA). The values were expressed as $\mathrm{pg} / \mathrm{mg}$ protein and $\mathrm{ng} / \mathrm{mg}$ protein.

\section{Cell culture and cell transfections}

The human cell line CD4+ cells and HEK293, were obtained from the National Infrastructure of Cell Line Resource (Chinese Academy of Medical Sciences). CD4+ cells were maintained in RPMI1640, supplemented with $10 \%$ fetal bovine serum (GeminiBio, USA) at $37^{\circ} \mathrm{C}$ in a $\mathrm{CO}_{2}$ incubator. $\mathrm{HEK} 293$ cells were maintained in DMEM, supplemented with $10 \%$ fetal bovine serum (GeminiBio, USA) at $37^{\circ} \mathrm{C}$ in a $\mathrm{CO}_{2}$ incubator.

Cells were transfected with the anti-miR-681 oligonucleotide $(100 \mathrm{nmol} / \mathrm{L})$ and scrambled negative control (Ambion) for $24 \mathrm{~h}$ using Lipofectamine 2000 (Invitrogen), followed by stimulation with LPS (100 $\mathrm{ng} / \mathrm{mL}$ ) for $24 \mathrm{~h}$.

\section{Intestinal lymphocyte isolation, flow cytometry, and FACS sorting}

Intestinal lymphocytes were harvested as previously described ${ }^{31}$. Briefly, small intestines were removed, opened longitudinally, and cut into $1-\mathrm{cm}$ pieces. The sections were washed with Hank's buffered saline and incubated in the presence of $5 \mathrm{mM}$ of EDTA at $37^{\circ} \mathrm{C}$ for $1 \mathrm{~h}$. After removing the released cells, gut tissues were digested with collagenase IV (100U, Sigma) at $37^{\circ} \mathrm{C}$ for $1 \mathrm{~h}$ and loaded onto a Percoll gradient and centrifuged. The cells between $40 \%$ and $100 \%$ Percoll were collected and used as intestinal lymphocytes.

Intestinal lymphocytes were mixed with the ammonium chloride lysis buffer (BioSource International, Inc., USA) to eliminate red blood cells and washed with RPMI containing 10\% FBS (GeminiBio). For T cell isolation, $\mathrm{CD}^{+} \mathrm{T}$ cell enrichment was performed using magnetic-activated cell sorting beads (Miltenyi Biotec, Bergisch Gladbach, Germany), followed by staining with an anti-CCR6 antibody for detecting miR- 
681 expression in living Th17 cells or followed by staining with an anti-IL-17 antibody for detecting the number of Th17 cells. In all subgroups of CD4+ T cells, only Th17 cells specifically express chemokine receptor type 6 (CCR6) ${ }^{32-35}$ and our result has proved that intestinal CD4+/CCR6+ T cells are IL-17producing T helper cells (Th17 cells) (Supplementary Figure 1).The Becton Dickinson FACSVantage system and MoFlo sorter (DAKOCytomation, Glostrup, Denmark) were used to detect fluorescence and sort cells, respectively.

\section{Immunofluorescence Microscopy}

Th17 cells were grown on glass coverslips, 48 hours after split, the cells were fixed with $4 \%$ polyformaldehyde for $10 \mathrm{~min}$, and incubated with PBS containing $0.1 \%$ Triton X-100 for $3 \mathrm{~min}$. IL-17 were detected with IL-17 antibodies and a Cy3-conjugated (red) secondary antibody (Jackson ImmunoResearch, Langcaster, Pennsylvania, USA). Coverslips were analyzed on the laser confocal fluorescence microscope (Leica TCS SP2, German).

\section{Bacterial cultures}

Bacterial detection was evaluated $24 \mathrm{~h}$ after LPS injection. To determine the CFU of $E$. coli, mesenteric lymph nodes (MLNs), spleens, and livers were harvested and homogenized in sterile phosphate-buffered saline (PBS), followed by serial dilutions and plating in Tryptic Soy Agar. The plates were incubated at $37^{\circ} \mathrm{C}$ for $24 \mathrm{~h}$, and colonies were counted.

\section{Northern blot analysis}

The miR-681 probes used for northern blotting were custom-designed and obtained from Shanghai Generay Biotech Co., Ltd. (Shanghai, China) as follows: miR-681, AGCTGCCTGCCAGCGAGGCTG and internal control U6, CACGGGAAGTCTGGGCTAAGAGACA. Northern blotting was performed according to the manufacturer's instructions. Briefly, $10 \mu \mathrm{g}$ of total RNA, which was isolated using the Ambion RNA extraction kit (Applied Biosystems, Foster City, CA, USA), was run on a 15\% acrylamide-bisacrylamide gel (19:1) containing $7 \mathrm{M}$ urea in Tris-borate-EDTA buffer. Following transfer onto a Hybond membrane (Amersham, Uppsala, Sweden) and ultraviolet crosslinking, the membrane was incubated with the radiolabeled hybridization probe in Ultra-Hyb-oligo hybridization buffer (Ambion). Subsequently, the membrane was washed thoroughly before exposure to X-ray films at $-70^{\circ} \mathrm{C}$.

\section{Chromatin immunoprecipitation (ChIP)}

Analysis of HIF-1 a binding to the miR-681 promoter was conducted using a ChIP assay kit (R\&D Systems, Minneapolis, MN, USA) according to the manufacturer's instructions. The primer sequences of the miR681 promoter were as follows: forward, TAAGCCAGCAGACACAGTTTAT; and reverse, ATGGTGCCACAACAAGGT.The custom-designed primers were purchased from Shanghai Generay Biotech Co., Ltd. Briefly, after fixation with formaldehyde, cell lysates were harvested and sonicated to shear chromatin. The mixtures were then centrifuged, and the supernatant was used for immunoprecipitation 
with anti-HIF-1 a antibody. After several washes, the resulting immunoprecipitates were used for PCR analysis using the aforementioned primers.

\section{Plasmid constructs and luciferase reporter assay}

The human 3'-UTR-Forward or -Reversesequence of the CCR6 gene were cloned into the Xbal/ Xbal site of the pGL3 control vector (Promega, Madison, WI, USA). For the luciferase reporter assay, cells were seeded into 96-well plates and transfected with pGL3-CCR6 + miR-681 mimic, pGL3-CCR6, pGL3-control + miR681 mimic, or pGL3-control, using Lipofectamine 2000 (Invitrogen). After 48 h, cells were harvested, washed with PBS, and subjected to a dual-luciferase reporter assay (Promega), according to the manufacturer's instructions and using a Lumat LB 9507 luminometer (Berthold, Nashua, NH, USA).

\section{Total RNA extraction and real-time PCR}

Total RNA was isolated from tissues and cells using the RNAgents Total RNA Isolation System (Promega), according to the manufacturer's instructions. Subsequently, $40 \mathrm{ng}$ of RNA was reversetranscribed into cDNA using the miRNA Reverse Transcription kit (Applied Biosystems). The TaqMan MicroRNA Assay Kit (Qiagen, Hilden, Germany) was used for real-time PCR analyses, using sequencespecific primers for CDNA synthesis and TaqMan probes for real-time PCR.

The expression of miRNAs was normalized to that of the rnu19 gene. Thirty novel miRNAs chosen from mouse embryos ${ }^{29}$ were quantitatively analyzed. Their sequences are listed in Table 1. All forward primers for miRNAs, shared-reverse miRNAs, and mRNAs were purchased from Guangzhou RiboBio Co., Ltd. (Guangzhou, China). The primer sequences of the ten differentially expressed miRNAs were as follows:

miRNA-681: CAGCCTCGCTGGCAGGCAGCT; miRNA-719, forward: ATCTCGGCTACAGAAAAATGTT; miRNA-711, forward: GGGACCCGGGGAGAGATGTAAG; miRNA-33: GTGCATTGTAGTTGCATTGCA; miRNA16-1: TAGCAGCACGTAAATATTGGCG; miRNA-345: GCTGACCCCTAGTCCAGTGCTT; miRNA-674-5p: GCACTGAGATGGGAGTGGTGTA; miRNA-301: GCTCTGACTTTATTGCACTACT; miRNA-143: GGTGCAGTGCTGCATCTCTGG; miRNA-695: AGATTGGGCATAGGTGACTGAA. 
Table 1

Thirty miRNAs from the expression profile of microRNAs in mouse embryos

\begin{tabular}{|ll|}
\hline Name & Sequence \\
\hline mmu-miR-678 & GUCUCGGUGCAAGGACUGGAGG \\
\hline mmu-miR-681 & CAGCCUCGCUGGCAGGCAGCU \\
\hline mmu-miR-153 & UUUGUGACGUUGCAGCU \\
\hline mmu-miR-410 & AGGUUGUCUGUGAUGAGUUCG \\
\hline mmu-miR-30b & UGUAAACAUCCUACACUCAGCU \\
\hline mmu-miR-540 & CAAGGUCACCCUCUGACUCUGU \\
\hline mmu-miR-615 & GGGGGUCCCCGGUGCUCGGAUC \\
\hline mmu-miR-27b & UUCACAGUGGCUAAGUUCUGC \\
\hline mmu-miR-497-3p & CAAACCACACUGUGGUGUUAG \\
\hline mmu-miR-370 & GCCUGCUGGGGUGGAACCUGGU \\
\hline mmu-miR-379 & UGGUAGACUAUGGAACGUAGG \\
\hline mmu-miR-412 & UUCACCUGGUCCACUAGCCG \\
\hline mmu-miR-711 & GGGACCCGGGGAGAGAUGUAAG \\
\hline mmu-miR-719 & AUCUCGGCUACAGAAAAAUGUU \\
\hline mmu-miR-615 & UCCGAGCCUGGGUCUCCCUCUU \\
\hline mmu-miR-688 & UCGCAGGCGACUACUUAUUC \\
\hline mmu-miR-691 & AUUCCUGAAGAGAGGCAGAAAA \\
\hline mmu-miR-693 & CAGCCACAUCCGAAAGUUUUC \\
\hline mmu-miR-301 & CAGUGCAAUAGUAUUGUCAAAG \\
\hline mmu-miR-345 & GCUGACCCCUAGUCCAGUGCUU \\
\hline mmu-miR-145 & GUCCAGUUUUCCCAGGAAUCCCU \\
\hline mmiR-miR-669b & AGUUUUGUGUGCAUGUGCAUGU \\
\hline AG-637 & UCAGCUCCUAUAUGAUGCCUUU \\
\hline CUGCAGUCACAGUGAAGUCUG
\end{tabular}




\begin{tabular}{|ll|}
\hline Name & Sequence \\
\hline mmu-miR-33 & GUGCAUUGUAGUUGCAUUGCA \\
\hline mmu-miR-16-1 & UAGCAGCACGUAAAUAUUGGCG \\
\hline mmu-miR-143 & GGUGCAGUGCUGCAUCUCUGG \\
\hline mmu-miR-674 & GCACUGAGAUGGGAGUGGUGUA \\
\hline
\end{tabular}

\section{Western blotting analysis}

After protein extraction from whole-cell lysates, total protein $(50 \mu \mathrm{g})$ was mixed with loading buffer containing sodium dodecyl sulfate (SDS) and $\beta$-mercaptoethanol and separated using $4-20 \%$ gradient SDS-polyacrylamide gel electrophoresis. After electrophoresis, proteins were transferred onto nitrocellulose membranes. Nonspecific binding sites on the membranes were blocked using skimmed milk protein. The membranes were incubated with primary antibodies against HIF-1a, CCR6, CCL20, or $\beta$ actin (all from Abcam, Cambridge, UK), followed by incubation with peroxidase-conjugated secondary antibodies. The signal was visualized using enhanced chemiluminescence reagent (Pierce, Rockford, IL, USA). The relative band intensities were determined using Gel-pro Analyzer software (Media Cybernetics, Bethesda, MD, USA).

\section{Statistical analysis}

For each experiment, three independent repeats were performed. Data are expressed as mean $\pm S D$. Statistical significance was determined using one-way or two-way ANOVA test for non-paired data or the Mann-Whitney U-test. The statistical significance in the survival analysis was determined by the log-rank test using GraphPad Prism software. A P-value of less than 0.05 was considered statistically significant.

\section{Results}

\section{Up-regulation of miR-681 in intestinal Th17 cells during endotoxemia}

Th17 cells have been implicated in the pathogenesis of several chronic inflammatory diseases, including rheumatoid arthritis and autoimmune encephalitis ${ }^{33,36}$. To investigate the miRNA expression profile in living Th17 cells in a mouse model of endotoxemia, we isolated Th17 cells from the small intestine of mice at $72 \mathrm{~h}$ after tail injection of LPS, followed by miRNA expression analysis. The analysis was performed by screening 30 miRNAs chosen from the expression profile of miRNAs in mouse embryos; we identified ten miRNAs that exhibited stable and significant changes in their expression in intestinal Th17 cells. The microRNAs miR-719, miR-711, miR-33, miR-681, miR-16-1, miR-345, miR-301, miR-143, miR-695, and miR-674 were upregulated in intestinal Th17 cells during endotoxemia. Among these ten miRNAs, miR-681 showed the strongest upregulation (Figure 1A). Next, we investigated miR-681 levels in circulating and intestinal Th17 cells in endotoxemia or E. coli-induced sepsis and found that miR-681 expression was remarkably elevated in small intestinal mucusa in both mouse models (Figure 1B). The 
induction of miR-681 in intestinal Th17 cells during endotoxemia was also confirmed by northern blot analysis (Figure 1C). We further examined jejunum tissues by FISH and found that miR-681 induction was restricted to IL-17-producing Th17 cells in intestinal villi. These findings suggested that $m i R-681$ was induced in intestinal Th17 cells in endotoxemic mice.

\section{HIF-1a mediates LPS-induced miR-681 up-regulation}

miR-681 was recently identified, and little is known about the regulation of its expression, targets, and function. We found that miR-681 expression was gradually elevated in intestinal Th17 cells in mice with LPS-induced endotoxemia (Figure 2A). HIF-1a has been previously implicated in intestinal barrier dysfunction ${ }^{37}$. Thus, we explored the potential links between HIF-1a and miR-681 during LPS stimulation. Sequence analysis of the miR-681 promoter region led to the identification of a putative hypoxia response element (HRE), suggesting that HIF could directly bind to the promoter region of miR-681 (Figure 2B). To verify this hypothesis, $1.5 \mathrm{~kb}$ of the miR-681 promoter region, as well as its HRE deletion mutant were cloned into luciferase reporter vectors (Figure 2B), which were then transfected into HEK293 cells. We found that LPS induced a 1.5-fold increase in the activity of the miR-681 promoter but not in the HRE mutant promoter (Figure 2C), indicating that LPS-induced miR-681 upregulation relies on the HRE found in the promoter region of miR-681. We further assessed whether miR-681 induction is mediated by HIF-1, using CD4+T cells treated with HIF-1a siRNA. LPS treatment induced miR-681 expression in CD4+T cells, but not in these with HIF-1a siRNA (Figure 2D). Moreover, ChIP analysis confirmed the binding of HIF-1a on the miR-681 promoter region during LPS stimulation (Figure 2E). Taken together, it implied that HIF-1a mediates LPS-induced miR-681 upregulation.

\section{Inhibition of miR-681 dramatically increases the number of intestinal Th17 cells during endotoxemia}

Our results demonstrated elevated levels of miR-681 in circulating and intestinal Th17 cells during endotoxemia (Figures 1 and 2). To assess the role of miR-681 in intestinal Th17 cells during endotoxemia in vivo, its expression was repressed by systemic injection of anti-miR-681. The expression of miR-681 in circulating and intestinal Th17 cells in endotoxemic mice was significantly reduced following systemic injection of anti-miR-681 (Figure 3A and B). Northern blot analysis confirmed the ability of systemic antimiR-681 administration to suppress the expression of miR-681 (Figure $3 \mathrm{C}$ and $\mathrm{D}$ ). We found that the administration of anti-miR-681 resulted in a profound increase in the number of intestinal Th17 cells (Figure 3E), while the number of circulating Th17 cells remained unchanged (Figure 3F), suggesting that blockade of miR-681 could result in the accumulation of Th17 cells in the small intestine. Furthermore, the intestinal levels of IL-17, which is mainly produced by Th17 cells in the small intestine, were also remarkably escalated after anti-miR-681 treatment (Figure 3G); however, the systemic levels of IL-17 were not altered by anti-miR-681. Collectively these suggested that miR- 681 might regulate the migration of Th17 cells to the intestine in endotoxemic mice.

CCR6-mediated recruitment of Th17 cells to the intestine mitigates intestinal inflammation in endotoxemic mice 
We next investigated the underlying mechanisms by which Th17 cells accumulated in the small intestine during endotoxemia. Th17 cells have been found to express the chemokine receptor CCR6, and several studies have demonstrated that CCR6-expressing Th17 cells are recruited to the inflamed location in rheumatoid arthritis and experimental autoimmune encephalomyelitis through the binding of CCL20 33,36 . Nevertheless, the role of CCR6 in the recruitment of Th17 cells to the intestine during endotoxemia has remained unclear. To assess the relevance of CCR6 in the migration of Th17 cells to the intestine, we treated wild-type (WT) and $C C R 6^{--}$mice with LPS. We found that the number of Th17 cells was significantly reduced in the intestine of $C C R 6^{-/-}$mice compared with WT mice (Figure 4A). The intestinal IL-17A levels in $C C R 6^{-/-}$mice were profoundly lower as well (Figure 4B). Intriguingly, we found that the high number of Th17 cells in the spleen and lymph nodes of $C C R 6^{--}$mice was accompanied by the enlargement of spleen and lymph nodes (data not shown), indicating that the absence of CCR6 did not impact the generation of Th17 cells.

Furthermore, the levels of inflammatory cytokines, including TNF-a and IL-6, were elevated in the small intestinal mucosa of $C C R \sigma^{-/-}$mice treated with LPS compared to WT mice (Figure $4 \mathrm{C}$ and D). By contrast, the levels of the anti-inflammatory cytokine IL-10 were dramatically decreased (Figure 4E), suggesting exacerbation of intestinal inflammation in $C C R \sigma^{-/-}$mice. We also found that the intestinal permeability and extent of bacterial invasion into the underlying tissues were higher in endotoxemic mice with CCR6 deficiency (Figure 4F and G). Given the low expression of CCL20 in the intestinal mucosa of CCR6 ${ }^{-/-}$mice during endotoxemia (Figure 4H), our data highlighted the importance of CCR6 in the migration of Th17 cells to the intestine, and implied that intestinal Th17 cells might reduce LPS-induced intestinal inflammation.

\section{miR-681 directly suppresses CCR6 expression during LPS stimulation}

Next, we analyzed whether miR-681 targets CCR6 expression during LPS stimulation. We found that miR681 could reduce CCR6 expression in CD4+T cells at $48 \mathrm{~h}$ after transfection with a miR-681 mimic (Figure $5 \mathrm{~A})$. We, therefore, investigated the effect of miR-681 on the 3c UTR of CCR6 using a miRNA Target Luciferase Reporter system. CCR6 3ç UTR and its reverse sequence (control 3c UTR) were cloned downstream of the luciferase reporter gene, the expression of which is regulated by a constitutive promoter. The constructs were transfected into HEK293 cells along with miR-681 mimic or a scrambled sequence oligonucleotide. We found that miR-681 mimic significantly decreased luciferase expression in luciferase-CCR6 3C UTR transfected cells, while the scrambled-sequence oligonucleotide only had a small effect (Figure 5B). As expected, neither of the sequences significantly changed luciferase expression in luciferase-control 3ç UTR transfected cells. Moreover, LPS treatment led to a mild increase in CCR6 expression. However, anti-miR-681 treatment significantly up-regulated CCR6 expression in CD4+T cells (Figure 5C). Importantly, in endotoxemic mice, the blockade of miR-681 resulted in a remarkable increase in CCR6 expression of intestinal Th17 cells (Figure 5D). Taken together, these robustly indicated that miR681 directly regulated CCR6 expression.

\section{Anti-miR-681 mitigates endotoxemia-induced intestinal injury}

Page $11 / 28$ 
To determine the role of miR-681 in endotoxemia-induced intestinal injury in vivo, systemic injection of anti-miR-681 was performed to attenuate miR-681 expression. We found that the administration of antimiR-681 significantly improved survival in endotoxemic mice (Figure 6A). We also evaluated endotoxemia-induced changes in gut integrity, villus length, and intestinal cell apoptosis. During endotoxemia, mice exhibited a $40 \%$ decrease in villus length, which was markedly restored by miR- 681 inhibition (Figure 6B and C). By quantifying the number of apoptotic cells per 100 crypts and 50 villi, we found that endotoxemia resulted in a significant increase in the level of apoptosis in the intestinal epithelium of crypts and villi (Figure 6D and E). Compared with mice injected with scrambled-sequence control, mice injected with anti-miR-681 exhibited profoundly lower levels of intestinal apoptosis in villi and crypts during endotoxemia (Figure 6D and E). Previous studies have shown that intestinal mucosal derangement in endotoxemia is accompanied by intestinal inflammation, increased permeability, and bacterial translocation. In endotoxemic mice, we found that anti-miR-681 repressed expression of the proinflammatory cytokines TNF- $a$ and IL- 6 in the small intestine, and elevated expression of the antiinflammatory cytokine IL-10, indicating that anti-miR-681 could alleviate intestinal inflammation in endotoxemic mice (Figure 6F and $\mathrm{H}$ ).

Furthermore, to assess intestinal permeability, the levels of diamine oxidase (DAO) in the bloodstream were measured in endotoxemia mice. The levels of circulating DAO in the serum of endotoxemic mice were remarkably reduced by administration of anti-miR-681 (Figure 6I). We also performed a quantitative analysis of the bacterial burden in MLNs, spleen, and liver. Intriguingly, we found a significant decrease in the bacterial burden in organs of endotoxemic mice treated with anti-miR-681 (Figure 6J-L). Our results showed that blocking miR-681 could protect against endotoxemia-induced intestinal injury.

\section{The protective effect of anti-miR-681 against endotoxemia-induced intestinal injury depends on CCR6- mediated recruitment of Th17 cells to the intestine}

In this study, we showed that the blockade of miR-681 facilitated Th17 cell accumulation in the intestine, reducing endotoxemia-induced intestinal injury. Given that CCR6 is required for Th17 cell recruitment to the intestine (Figure $7 \mathrm{~A}$ ), we used $C C R 6^{-1-}$ mice to confirm the role of intestinal Th17 cell accumulation in anti-miR-681-mediated intestinal protection during endotoxemia. TNF- $a$ and IL- 6 levels were significantly elevated, while IL-10 levels were reduced in the intestinal mucosa of $C C R 6^{-1-}$ mice with or without antimiR-681 treatment during endotoxemia (Figure 7B-D), suggesting that in the absence of CCR6, the intestinal inflammation induced by endotoxemia was aggravated. Next, we found that CCR6 deficiency could exacerbate intestinal barrier dysfunction, intestinal hyperpermeability, and bacterial translocation in MLNs, spleen, and liver, despite the administration of anti-miR-681 (Figure 7E-H).

Additionally, we found that compared with WT mice, $C C R 6^{-1-}$ mice had shorter villi, and exhibited higher levels of crypt and villus epithelial apoptosis during endotoxemia (Figure 7I-K). Importantly, CCR6 ${ }^{-1}$ mice treated with anti-miR-681 had higher levels of apoptosis during endotoxemia compared with WT mice treated with anti-miR-681 (Figure $7 \mathrm{~L}$ ). Taken together, our data indicated that the protective effects of 
miR-681 down-regulation against endotoxemia-induced intestinal injury relied on the recruitment of Th17 cells to the intestine through CCR6.

\section{Discussion}

In this study, we identified a miRNA, miR-681, regulating the recruitment of Th17 cells to the intestine, which affects intestinal epithelial barrier function during endotoxemia. We found that miR-681 has a critical role in preventing the Th17 cell migration to the intestine during endotoxemia. In vitro experiments led to the identification of the chemokine receptor CCR6 as a direct target of miR-681. The blockade of miR-681 resulted in increased CCR6 expression, facilitating the recruitment of Th17 cells to the intestine. The intestinal Th17 cell accumulation prevented endotoxemia-induced intestinal injury, which involves intestinal inflammation, increased intestinal permeability, bacterial translocation, and enhanced intestinal apoptosis. Anti-miR-681-mediated intestinal Th17 cell accumulation also prolonged survival in mice with LPS-induced endotoxemia. To our knowledge, few other single miRNAs have been shown to modulate intestinal epithelial damage following endotoxemia by regulating intestinal immune cells.

Th17 cells play protective roles against extracellular bacterial infections in the gut mucosa. The presence of Th17 cells and their major effector cytokine, IL-17, in the lamina propria conferred resistance to Citrobacter rodentium infection in mice ${ }^{38,39}$. In addition, IL-22, which is primarily secreted by Th17 cells, has been shown to potentiate the host defense against $C$. rodentium by enhancing the expression of antimicrobial proteins of the Reg family in colonic epithelial cells ${ }^{40}$. This is further supported by our findings showing that the increased recruitment of Th17 to the intestine could significantly allay intestinal inflammation, reduce intestinal permeability, and prevent intestinal injury following endotoxemia. However, the function of Th17 cells in response to infections can be a double-edged sword; the balance between the protective and pathogenic roles of Th17 cells may determine the outcome of the infection. Th17 and IL-17 have been demonstrated to elicit an inflammatory infiltration of neutrophils in response to $H$. pylori-induced gastritis ${ }^{41,42}$. In inflammatory bowel diseases, Th17 cells and IL-17 have been linked to intestinal inflammation, and the in vivo transfer of Th17 cells from experimental colitis into lymphopenic mice could lead to the development of colitis ${ }^{34,43-45}$. Our findings, however, provided evidence of the protective roles of intestinal Th17 cells. This suggests that mature Th17 cells may have several yet unknown intrinsic mechanisms that ensure homeostasis and prevent excessive Th17 cell activation. Future studies are required to elucidate such mechanisms.

Th17 cells are abundant in intestinal mucosal interfaces, where infections with pathogenic bacteria and fungi could occur. Under physiological conditions, the number of Th17 cells is low in mice and humans $^{35,46}$. However, under pathological conditions, the cytokines TGF- $\beta$, IL-1 $\beta$, and IL- 6 induce RORyt expression in human and mouse naïve T cells located in intestinal lamina propria, resulting in the development of Th17 cells ${ }^{47-49}$. Additionally, during bacterial and viral infections, increased circulatory Th17 cells expressing the chemokine receptor CCR6 are preferentially recruited to the intestinal epithelium, where CCL20 is secreted at high levels ${ }^{11}$. Interestingly, Th17 cells in the intestine promote 
further recruitment of circulatory Th17 cells to the intestine. This positive feedback loop is mediated by IL-17-induced release of CCL20 from intestinal epithelial cells and can result in the robust accumulation of Th17 cells in the intestine. In this study, we showed that during endotoxemia, CCR6 deficiency significantly reduced the number of Th17 cells in the small intestine, indicating that CCR6 is mainly, if not solely, responsible for the recruitment of Th17 cells to the intestine in endotoxemic mice. Of course, the possibility that gut-resident Th17 cells also contribute to the observed phenomenon cannot be excluded. Furthermore, we found that a single miRNA, miR681, could directly regulate CCR6 expression in vitro. The regulation of CCR6 expression in T cells by miRNAs has been reported in T-cell lymphoma, where miR-

68150 has been demonstrated to inhibit tumor invasion and metastasis by targeting CCR6 expression ${ }^{50}$. In the future, additional miRNAs targeting CCR6 in T cells are likely to be identified.

\section{Conclusions}

In conclusion, our study highlighted miR-681 as a critical miRNA modulating endotoxemia-induced intestinal injury by regulating CCR6 expression in Th17 cells. The elucidation of the HIF-1a/miR$681 /$ CCR6 axis not only provides novel and vital insight into the pathogenesis of intestinal injury but also suggests a new miRNA-based therapeutic target for the prevention and treatment of endotoxemia.

\section{Abbreviation}

Th17 cells IL-17-producing CD4+ T-helper cells

CD4 cluster of Differentiation 4

LPS lipopolysaccharide

TCR T cell receptor

IL interleukin

miR microRNAs

CCR6 chemokine receptor 6

TUNEL TdT-mediated dUTP Nick-End Labeling

FISH fluorescence in situ hybridization

PBS phosphate-buffered saline

CFU colony forming units

MEF mouse embryonic fibroblast 
MLN mesenteric lymph node

ChIP chromatin immunoprecipitation

HIF-1a hypoxia inducible factor-1a

CCL20 chemokine (C-C motif) ligand 20

\section{Declarations}

\section{Ethics approval and consent to participate}

All experiments involving animals were approved by the Animal Care and Use Committee of the Sun Yatsen University, Guangzhou, China.

\section{Consent for publication}

The informed consent obtained from study participants.

\section{Availability of data and materials}

All data generated or analysed during this study are included in this published article.

\section{Competing interests}

No conflicts of interest, financial or otherwise, are declared by the authors.

\section{Funding}

The study was supported by Grants-in-Aid mostly from Zhihao Liu with National Natural Scientific Foundation of China $(82172158,81602660)$, Guangdong Natural Science Foundation (2016A030310159), slightly from Qingli Zeng with Science and technology program of Guangdong Province (2014A020212150), Chuanxi Chen with Medical Scientific Research Foundation of Guangdong Province(A2018046) and Jinli Liao with The Directive Project of Medical Research Fund of Guangdong Province (C2019105)

\section{Authors' contributions}

LW Gu, J Jiang and ZG Liu contributed equally to this work; ZH Liu and CX C designed the research; CX C, ZG Liu, J Jiang, QQ Liu, JL Liao, QL Zeng performed the research; ZH Liu, LW Gu, and CX C analyzed the data; ZH Liu and QL Zeng Contributed reagents/materials/analysis tools; ZH Liu, LW Gu and CX C wrote the paper.

\section{Acknowledgements}


We thank Prof. Dr. Lijuan Jiang and Dr. Lijin Zeng at the Sun Yat-sen University in China for counting apoptotic index. We thank other members of our laboratories for helpful discussions and comments.

\section{Authors' information}

Authors including Liwen Gu, Qiangqiang Liu, Jinli Liao, Qingli Zeng, Zhihao Liu are from Division of Emergency Medicine, Department of Emergency Intensive Care Unit, The First Affiliated Hospital of Sun Yat-sen University, No.58, Zhongshan 2nd Road, Guangzhou, 510080, China

Author Jie Jiang is from Department of Gastroenterology, The Third Affiliated Hospital of Sun Yat-Sen University, No.600, Tianhe Road, Guangzhou, 510360,China

Author Zhigang Liu is from Department of head and neck oncology, Phase 1 clinical trial ward, The cancer center of The Fifth Affiliated Hospital of Sun Yat-sen University, Zhuhai, 519001, China

Author Chuanxi Chen is from Department of Surgical Intensive Care Unit, The First Affiliated Hospital of Sun Yat-sen University, No.58, Zhongshan 2nd Road, Guangzhou, 510080, China

\section{References}

1. Hotchkiss RS, Karl IE. The pathophysiology and treatment of sepsis. N Engl J Med. 2003 Jan 9;348(2):138-50.

2. Guo S, Nighot M, Al-Sadi R, Alhmoud T, Nighot P, Ma TY. Lipopolysaccharide Regulation of Intestinal Tight Junction Permeability Is Mediated by TLR4 Signal Transduction Pathway Activation of FAK and MyD88.J Immunol. 2015;195(10):4999-5010.

3. Moriez R, Salvador-Cartier C, Theodorou V, Fioramonti J, Eutamene H, Bueno L. Myosin light chain kinase is involved in lipopolysaccharide-induced disruption of colonic epithelial barrier and bacterial translocation in rats.Am J Pathol. 2005 Oct;167(4):1071-9.

4. Zong X, Hu W, Song D, Li Z, Du H, Lu Z, Wang Y. Porcine lactoferrin-derived peptide LFP-20 protects intestinal barrier by maintaining tight junction complex and modulating inflammatory response.Biochem Pharmacol. 2016;104:74-82.

5. Clark JA, Coopersmith CM.Intestinal crosstalk: a new paradigm for understanding the gut as the "motor" of critical illness.Shock. 2007;28(4):384-93.

6. Hassoun HT, Kone BC, Mercer DW, Moody FG, Weisbrodt NW, Moore FA. Post-injury multiple organ failure: the role of the gut.Shock. 2001;15(1):1-10.

7. Coopersmith CM, Strongberg PE, Dunne WM, Davis CG, Amiot DM, Buchman TG, Karl IE, Hotchkiss RS. Inhibition of intestinal epithelial apoptosis and survival in a murine model of pneumonia-induced sepsis. JAMA 2002;287(13):1716-21.

8. Dominguez JA, Samocha AJ, Liang Z, Burd EM, Farris AB, Coopersmith CM.Inhibition ofIKKßin enterocytes exacerbates sepsis-induced intestinal injury andworsens mortality.Crit Care Med2013;41(10):e275-85. 
9. Li Y, Li Q, Chen H, Wang T, Liu L, Wang G, Xie K, Yu Y.Hydrogen Gas Alleviates the Intestinal Injury Caused by SevereSepsis in Mice by Increasing the Expression of Heme Oxygenase-1.Shock 2015;44(1):90-8.

10. Hall PA, Coates PJ, Ansari B, Hopwood D.Regulation of cell number in the mammalian gastrointestinal tract: the importance of apoptosis. J Cell Sci. 1994;107 (Pt 12):3569-77

11. Huber S, Gagliani N, Flavell RA.Life, death, and miracles: Th17 cells in the intestine.Eur J Immunol. 2012 Sep;42(9):2238-45.

12. Bettelli E, Carrier Y, Gao W, Korn T, Strom TB, Oukka M, Weiner HL, Kuchroo VK.Reciprocal developmental pathways for the generation of pathogenic effector TH17 and regulatory T cells.Nature. 2006;441(7090):235-8.

13. Ivanov II, McKenzie BS, Zhou L, Tadokoro CE, Lepelley A, Lafaille JJ, Cua DJ, Littman DR.The orphan nuclear receptor RORgammat directs the differentiation program of proinflammatory IL-17+ T helper cells.Cell. 2006 Sep 22;126(6):1121-33.

14. Kleinschek MA, Boniface K, SadekovaS, GreinJ, Murphy EE,Turner SP, RaskinL, Desai B, Faubion WA, de Waal Malefyt R, Pierce RH, McClanahan T, Kastelein RA. Circulating and gut-resident human Th17cells express CD161 and promote intestinal inflammation. JExp Med.2009;206: 525-534.

15. Lee YK, Turner H, Maynard CL, OliverJR, Chen D, Elson CO and Weaver CT. Late developmental plasticity in the T helper 17lineage. Immunity 2009;30: 92-107.

16. WangC, Kang SG, Lee J, Sun Z and Kim CH. The roles of CCR6in migration of Th17 cells and regulation of effector T-cell balance in thegut. Mucosal Immunol. 2009;2: 173-183.

17. Elson CO, CongY, Weaver CT, Schoeb TR, McClanahanTK,Fick RB and Kastelein RA. Monoclonal antiinterleukin 23 reversesactive colitis in a T cell-mediated model in mice. Gastroenterology 2007;132: 2359-2370.

18. Huber S, Gagliani N, Esplugues E, O’Connor WJr, HuberFJ,Chaudhry A, Kamanaka M,Kobayashi Y, Booth CJ, Rudensky AY, Roncarolo MG, Battaglia M, Flavell RA. Th17 cells express interleukin10mreceptor and are controlled by Foxp3 and Foxp3+ regulatory CD4+ T cellsin an interleukin-10dependent manner. Immunity 2011. 34: 554-565.

19. Khader SA, Gaffen SL, Kolls JK. Th17 cells at the crossroads of innate and adaptive immunity against infectiousdiseases atthe mucosa. Mucosal Immunol. 2009;2(5):403-11.

20. Ogawa A, Andoh A, Araki Y, Bamba T and FujiyamaY. Neutralization of interleukin-17 aggravates dextran sulfate sodium-induced colitisin mice. Clin Immunol. 2004;110: 55-62.

21. Yang XO, Chang SH, Park H, Nurieva R, Shah B, Acero L,WangYH, Schluns KS, Broaddus RR, Zhu Z, Dong C. Regulation of inflammatory responses by IL-17F. J Exp Med.2008;205: 1063-1075.

22. Zheng Y, Valdez PA, Danilenko DM, Hu Y, Sa SM, Gong Q, Abbas AR, Modrusan Z, Ghilardi N, de Sauvage FJ, Ouyang W.Interleukin-22 mediates early host defense against attaching and effacing bacterialpathogens.Nat Med. 2008;14(3):282-9.

23. Gagliani N, Amezcua Vesely MC, Iseppon A, Brockmann L, Xu H, Palm NW, de Zoete MR, LiconaLimón P, Paiva RS, Ching T, Weaver C, Zi X, Pan X, Fan R, Garmire LX, Cotton MJ, Drier Y, Bernstein B, 
Geginat J, Stockinger B, Esplugues E, Huber S, Flavell RA.Th17 cells transdifferentiate into regulatory T cells during resolution of inflammation.Nature. 2015;523(7559):221-5.

24. Mendell JT, Olson EN. MicroRNAs in stress signaling and human disease.Cell 2012;148(6):11721187.

25. Neudecker V, Haneklaus M, Jensen O,Khailova L, Masterson JC, Tye H, Biette K, Jedlicka P, Brodsky KS, Gerich ME, Mack M, Robertson AAB, Cooper MA, Furuta GT, Dinarello CA, O'Neill LA, Eltzschig HK, Masters SL, McNamee EN. Myeloid-derived miR-223 regulates intestinal inflammation via repression of the NLRP3 inflammasome. J Exp Med. 2017;214(6):1737-1752.

26. He C, Yu T, Shi Y, Ma C, Yang W, Fang L, Sun M, Wu W, Xiao F, Guo F, Chen M, Yang H, Qian J, Cong Y, Liu Z.MicroRNA 301APromotes Intestinal Inflammation and Colitis-Associated Cancer Development by Inhibiting BTG1.Gastroenterology. 2017;152(6):1434-1448.

27. Neudecker V, Yuan X, Bowser JL, Eltzschig HK. MicroRNAs in mucosal inflammation. J Mol Med (Berl). (2017)95(9):935-949.

28. Nakata K, Sugi Y, Narabayashi H, Kobayakawa T, Nakanishi Y, Tsuda M, Hosono A, Kaminogawa S, Hanazawa S, Takahashi K. Commensal microbiota-induced microRNA modulates intestinal epithelial permeability through the small GTPase ARF4. J Biol Chem 2017;292(37):15426-15433.

29. Mineno J, Okamoto S, Ando T, Sato M, Chono H, Izu H, et al. The expression profile of microRNAs in mouse embryos. Nucleic Acids Res 2006;34(6):1765-1771.

30. Wahlquist C, Jeong D, Rojas-Muñoz A, Kho C, Lee A, Mitsuyama S, van Mil A, Park WJ, Sluijter JP, Doevendans PA, Hajjar RJ, Mercola M.Inhibition of miR-25 improves cardiac contractility in the failing heart.Nature 2014, 508(7497):531-535.

31. Kamanaka M, Kim ST, Wan YY, Sutterwala FS, Lara-Tejero M, Galan JE, Harhaj E, Flavell RA. Expression of interleukin-10 in intestinal lymphocytes detected by an interleukin-10 reporter knockin tiger mouse. Immunity. (2006)25(6):941-52.

32. Francesco Annunziato, Lorenzo Cosmi, Veronica Santarlasci, Laura Maggi, Francesco Liotta, Benedetta Mazzinghi, Eliana Parente, Lucia Filì, Simona Ferri, Francesca Frosali, Francesco Giudici, Paola Romagnani, Paola Parronchi, Francesco Tonelli, Enrico Maggi, Sergio Romagnani. Phenotypic and functional features of human Th17 cells. J Exp Med. 2007;204(8):1849-61.

33. Keiji Hirota, Hiroyuki Yoshitomi, Motomu Hashimoto, Shinji Maeda, Shin Teradaira, Naoshi Sugimoto, Tomoyuki Yamaguchi, Takashi Nomura, Hiromu Ito, Takashi Nakamura, Noriko Sakaguchi, Shimon Sakaguchi. Preferential recruitment of CCR6-expressing Th17 cells to inflamed joints via CCL20 in rheumatoid arthritis and its animal model. J Exp Med. 2007;204(12):2803-12.

34. C Wang, S G Kang, J Lee, Z Sun, C H Kim. The roles of CCR6 in migration of Th17 cells and regulation of effector T-cell balance in the gut. Mucosal Immunol. 2009;2(2):173-83.

35. Enric Esplugues, Samuel Huber, Nicola Gagliani, Anja E Hauser, Terrence Town, Yisong Y Wan, William O'Connor Jr, Anthony Rongvaux, Nico Van Rooijen, Ann M Haberman, Yoichiro Iwakura, Vijay K Kuchroo, Jay K Kolls, Jeffrey A Bluestone, Kevan C Herold, Richard A Flavell. Control of TH17 cells occurs in the small intestine. Nature. 2011;475(7357):514-8. 
36. Reboldi A, Coisne C, Baumjohann D, Benvenuto F, Bottinelli D, Lira S, Uccelli A, Lanzavecchia A, Engelhardt B, Sallusto F. C-C chemokine receptor 6-regulated entry of $\mathrm{TH}-17$ cells into the CNS through the choroid plexus is required for the initiation of EAE. Nat Immunol. 2009 May;10(5):51423. doi: 10.1038/ni.1716. Epub 2009 Mar 22. PMID: 19305396.

37. Shao T, Zhao C, Li F, Gu Z, Liu L, Zhang L, Wang Y, He L, Liu Y, Liu Q, Chen Y, Donde H, Wang R, Jala VR, Barve S, Chen SY, Zhang X, Chen Y, McClain CJ, Feng W.Intestinal HIF-1 a deletion exacerbates alcoholic liver disease by inducing intestinal dysbiosis and barrier dysfunction.J Hepatol. 2018;69(4):886-895.

38. Mangan PR, Harrington LE, O'Quinn DB, Helms WS, Bullard DC, Elson CO, Hatton RD, Wahl SM, Schoeb TR, Weaver CT. Transforming growth factor-beta induces development of the $T(H) 17$ lineage.Nature. 2006;441(7090):231-4.

39. Ishigame H, Kakuta S, Nagai T, Kadoki M, Nambu A, Komiyama Y, Fujikado N, Tanahashi Y, Akitsu A, Kotaki H, Sudo K, Nakae S, Sasakawa C, Iwakura Y.Differential roles of interleukin-17A and -17F in host defense against mucoepithelial bacterial infection and allergic responses.Immunity. 2009;30(1):108-19.

40. Zheng Y, Valdez PA, Danilenko DM, Hu Y, Sa SM, Gong Q, Abbas AR, Modrusan Z, Ghilardi N, de Sauvage FJ, Ouyang W.Interleukin-22 mediates early host defense against attaching and effacing bacterial pathogens.Nat Med. 2008;14(3):282-9.

41. Luzza F, Parrello T, Monteleone G, Sebkova L, Romano M, Zarrilli R, Imeneo M, Pallone F. Upregulation of IL-17 is associated with bioactive IL-8 expression in Helicobacter pylori-infected human gastric mucosa.J Immunol. 2000;165(9):5332-7.

42. Caruso R, Fina D, Paoluzi OA, Del Vecchio Blanco G, Stolfi C, Rizzo A, Caprioli F, Sarra M, Andrei F, Fantini MC, MacDonald TT, Pallone F, Monteleone G.IL-23-mediated regulation of IL-17 production in Helicobacter pylori-infected gastric mucosa.Eur J Immunol. 2008;38(2):470-8.

43. Kleinschek MA, Boniface K, Sadekova S, Grein J, Murphy EE, Turner SP, Raskin L, Desai B, Faubion WA, de Waal Malefyt R, Pierce RH, McClanahan T, Kastelein RA.Circulating and gut-resident human Th17 cells express CD161 and promote intestinal inflammation.J Exp Med. 2009;206(3):525-34.

44. Seiderer J, Elben I, Diegelmann J, Glas J, Stallhofer J, Tillack C, Pfennig S, Jürgens M, Schmechel S, Konrad A, Göke B, Ochsenkühn T, Müller-Myhsok B, Lohse P, Brand S.Role of the novel Th17 cytokine IL-17F in inflammatory bowel disease (IBD): upregulated colonic IL-17F expression in active Crohn's disease and analysis of the IL17F p.His161 Arg polymorphism in IBD.Inflamm Bowel Dis. 2008;14(4):437-45.

45. Huber S, Gagliani N, Esplugues E, O'Connor W Jr, Huber FJ, Chaudhry A, Kamanaka M, Kobayashi Y, Booth CJ, Rudensky AY, Roncarolo MG, Battaglia M, Flavell RA.Th17 cells express interleukin-10 receptor and are controlled byFoxp3- and Foxp3+ regulatory CD4+ T cells in an interleukin-10dependent manner.Immunity. 2011;34(4):554-65.

46. Korn T, Bettelli E, Oukka M, Kuchroo VK.IL-17 and Th17 Cells.Annu Rev Immunol. 2009;27:485-517. 
47. Bettelli E, Carrier Y, Gao W, Korn T, Strom TB, Oukka M, Weiner HL, Kuchroo VK.Reciprocal developmental pathways for the generation of pathogenic effector $\mathrm{TH} 17$ and regulatory $\mathrm{T}$ cells.Nature. 2006;441(7090):235-8.

48. Veldhoen M, Hocking RJ, Atkins CJ, Locksley RM, Stockinger B.TGFbeta in the context of an inflammatory cytokine milieu supports de novo differentiation of IL-17-producing T cells.Immunity. 2006;24(2):179-89.

49. Mangan PR, Harrington LE, O'Quinn DB, Helms WS, Bullard DC, Elson CO, Hatton RD, Wahl SM, Schoeb TR, Weaver CT.Transforming growth factor-beta induces development of the $T(H) 17$ lineage.Nature. 2006 May 11;441(7090):231-4.

50. Ito M, Teshima K, Ikeda S, Kitadate A, Watanabe A, Nara M, Yamashita J, Ohshima K, Sawada K, Tagawa H.MicroRNA-150 inhibits tumor invasion and metastasis by targeting the chemokinereceptor CCR6,in advanced cutaneous T-cell lymphoma.Blood. 2014;123(10):1499-511.

\section{Figures}


A
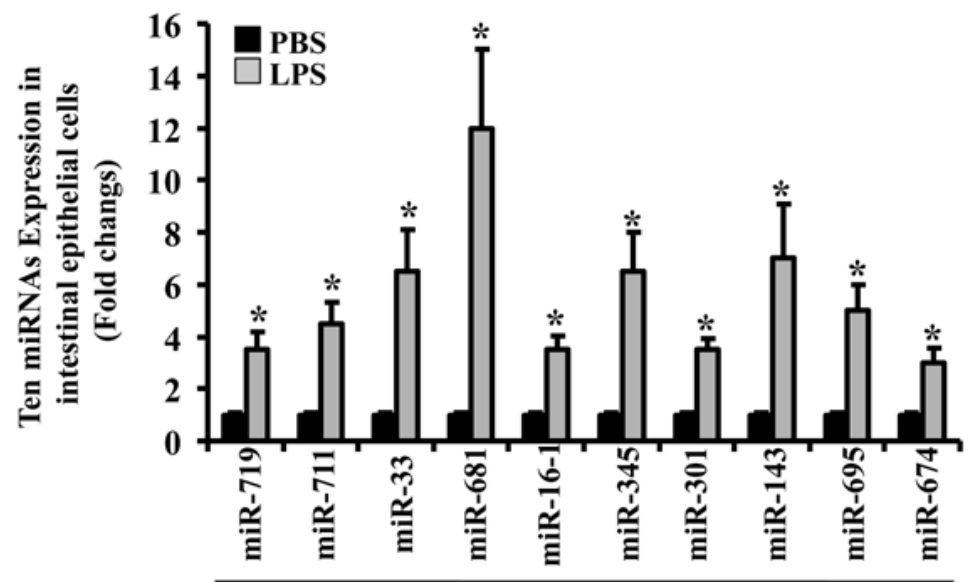

Intestinal Th 17 cells

$\mathbf{C}$

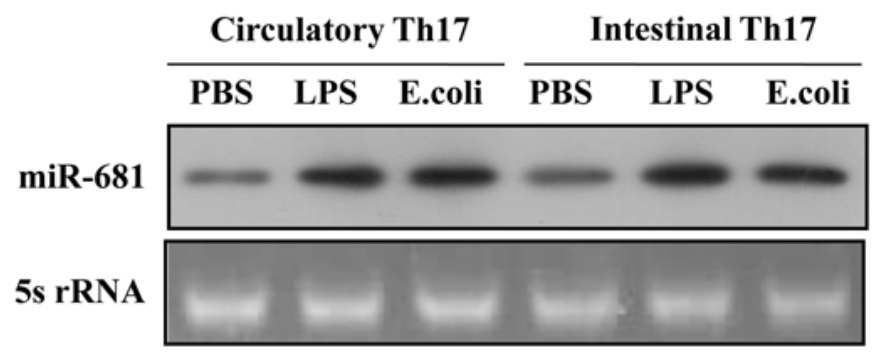

B

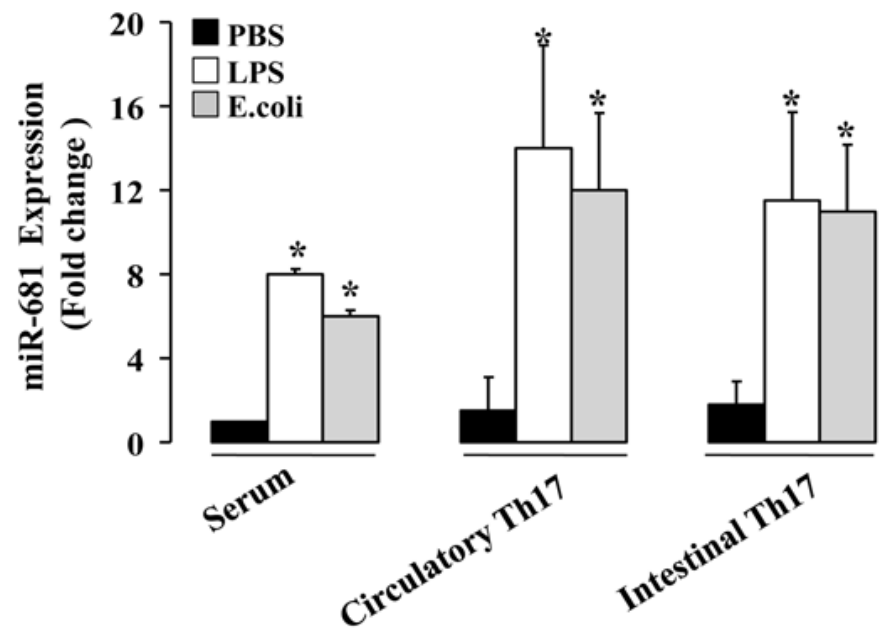

D

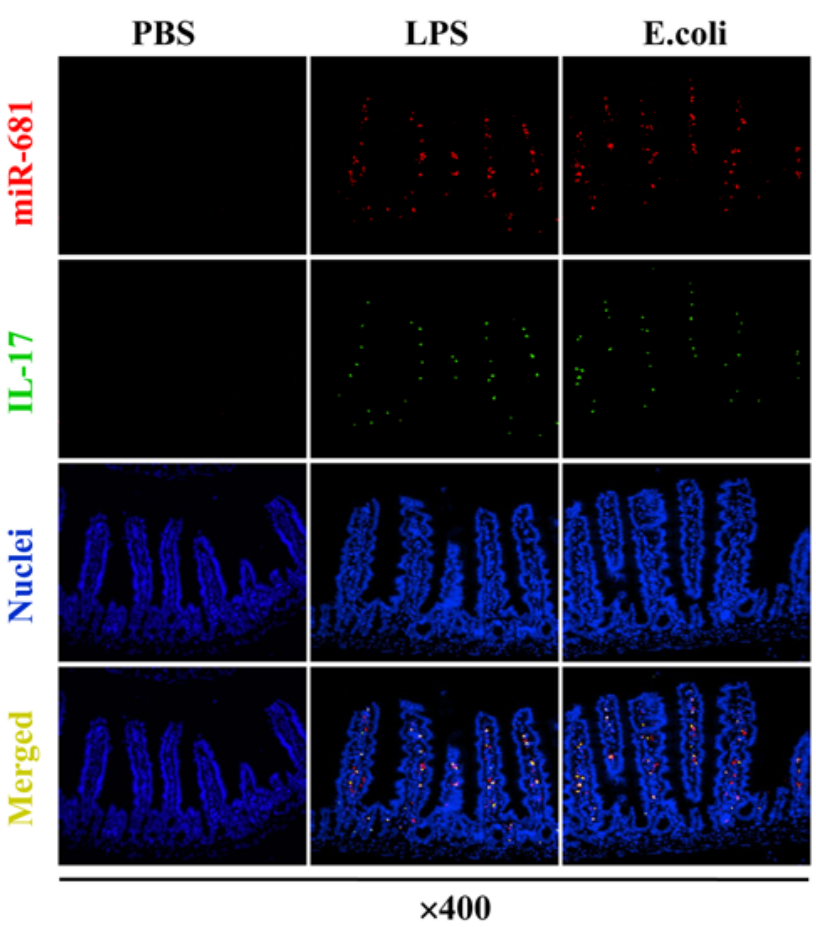

Figure 1

Up-regulation of miR-681 in intestinal Th17 cells during endotoxemia. A Significant changes in the expression of ten miRNAs in intestinal Th17 cells of endotoxemia mice. Intestinal Th17 cells were collected $72 \mathrm{~h}$ after LPS injection. Data are represented as mean $\pm S D, n=8$ in each group. ${ }^{*}<0.05$ vs. PBS. B Real-time PCR for miR-681. RNA from intestinal Th17 cells collected $72 \mathrm{~h}$ after LPS injection. Data are represented as mean $\pm S D, n=6$ in each group. ${ }^{*} P<0.05$ vs. PBS. $C$ Northern blot analysis of miR681. Ten micrograms of the total RNA extracted from Th17 cells $72 \mathrm{~h}$ after LPS injection was used for northern blot analysis. 5s rRNA was probed as a loading control. D Immunofluorescence staining of frozen sections of the small intestine dissected $72 \mathrm{~h}$ after LPS injection (miR-681, red; IL-17, green; cell nuclei, DAPI). Magnifications: $\times 400$. Data are representative of at least three independent experiments. 


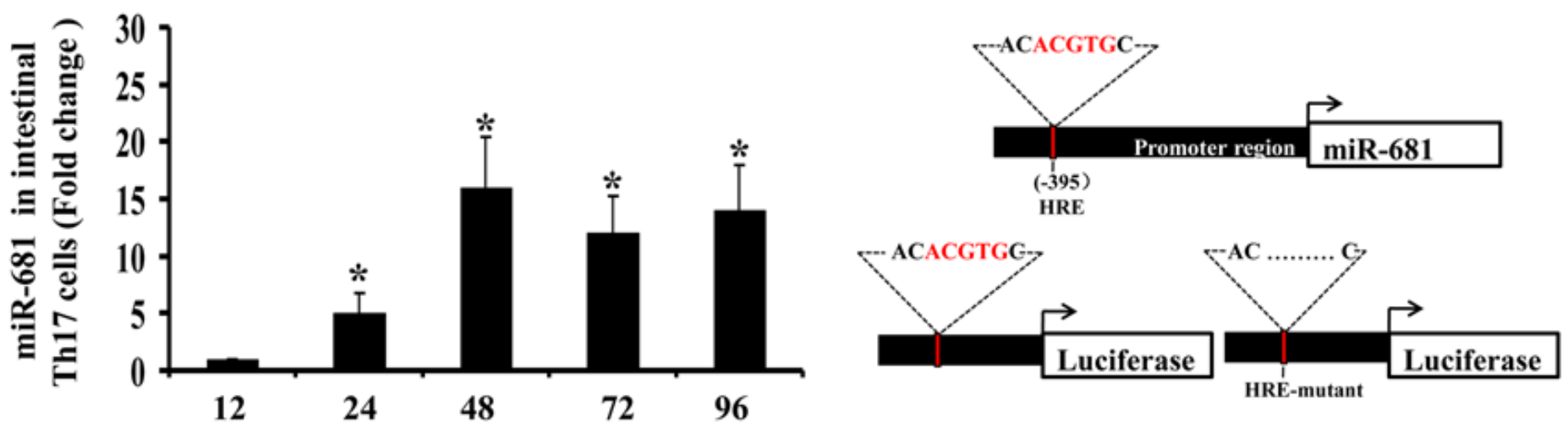

After LPS injection (hours)
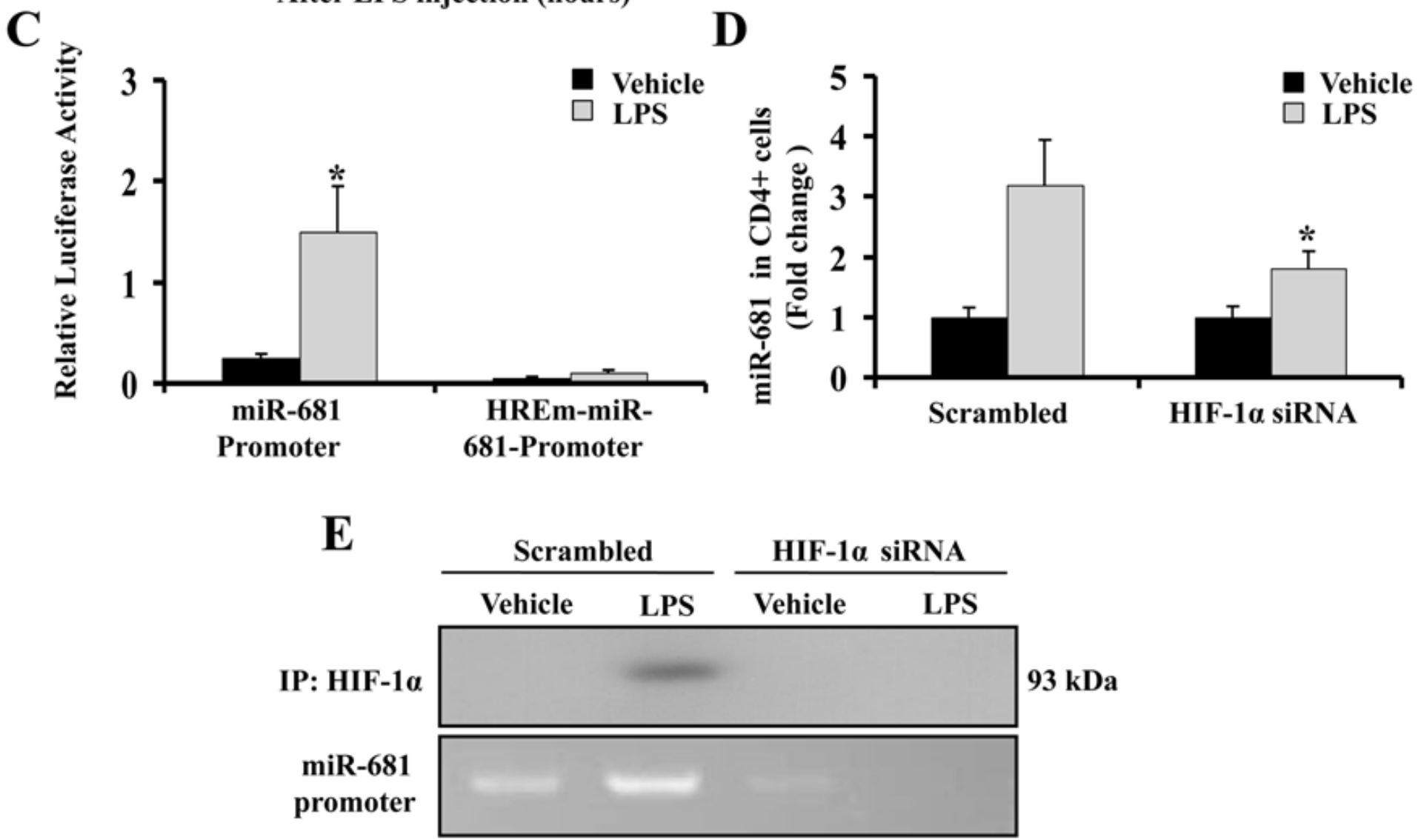

Figure 2

HIF-1a mediates LPS-induced miR-681 up-regulation. A Induction of miR-681 in intestinal Th17 cells from endotoxemic mice. Fold changes relative to the values in intestinal Th17 cells from control mice (arbitrarily set as 1 ) are shown. ${ }^{*} \mathrm{P}<0.05 \mathrm{vs} .0 \mathrm{~h}$. B miR-681 promoter region harboring putative HRE or HIF binding sites (upper panel). Reporter vectors containing the miR-681 promoter with or without HRE upstream of the luciferase gene (lower panel). C Activation of the miR-681 promoter by LPS. miR-681 promoter and its HIF binding site-deletion mutant were subcloned upstream of the luciferase gene in the reporter construct. HEK293 were co-transfected with one of these reporter constructs, along with the Renilla luciferase construct, in a ratio of 2:0.1. Cells were then subjected to LPS stimulation for $2 \mathrm{~h}$, and 
lysates were collected for luciferase activity measurement. D Induction of miR-681 expression in response to LPS stimulation in CD4+ T cells treated with HIF-1a siRNA. The cells were subjected to LPS stimulation for $2 \mathrm{~h}$, followed by RNA isolation for real-time PCR analysis for miR-681. * $P<0.05$ vs. Scrambled treated with LPS. E HIF-1a binding to the miR-681 promoter during LPS stimulation. CD4+ T cells pre-treated with HIF-1 a scrambled and siRNAwere treated with LPS for $2 \mathrm{~h}$. Cell lysates were collected for ChIP analysis assessing HIF-1a binding to the miR-681 promoter region.

A

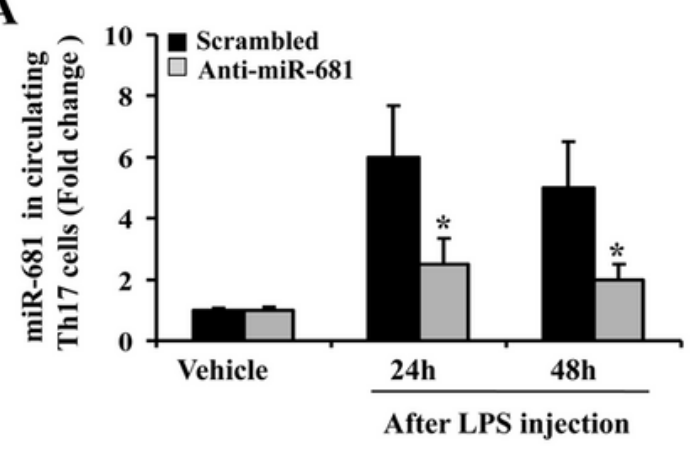

C

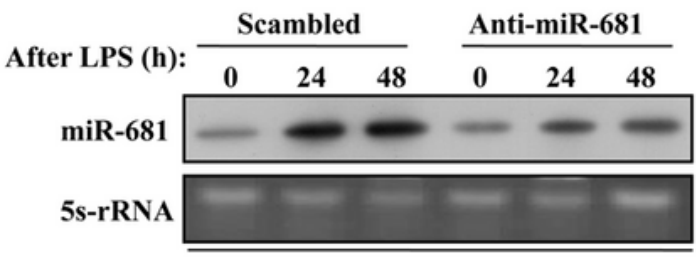

Circulating Th 17 cells

$\mathbf{E}$
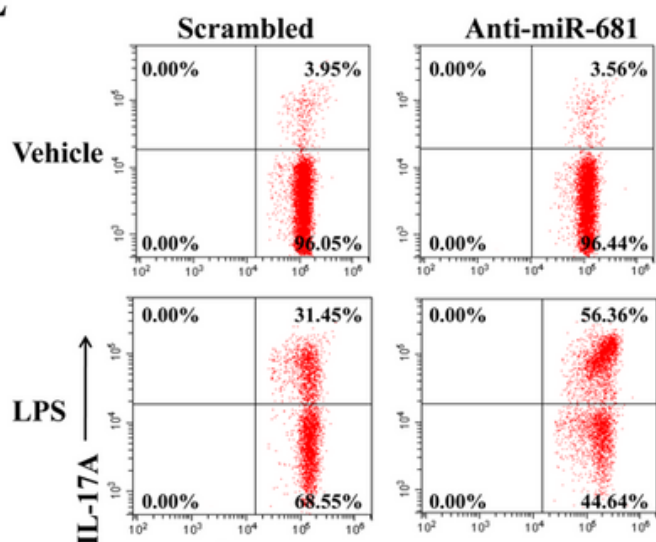

CD4

Th 17 cells in small intestine

G

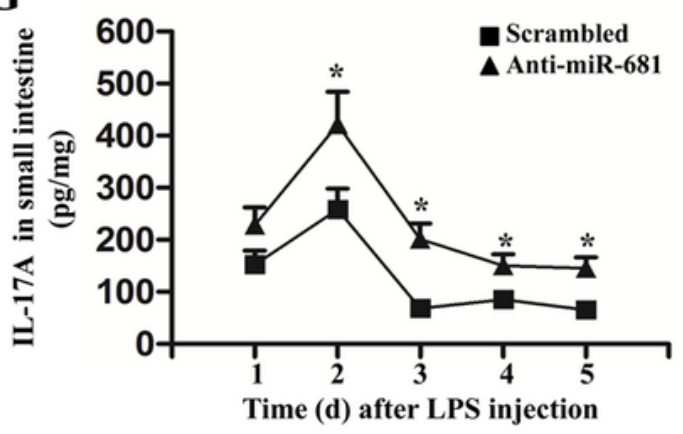

B

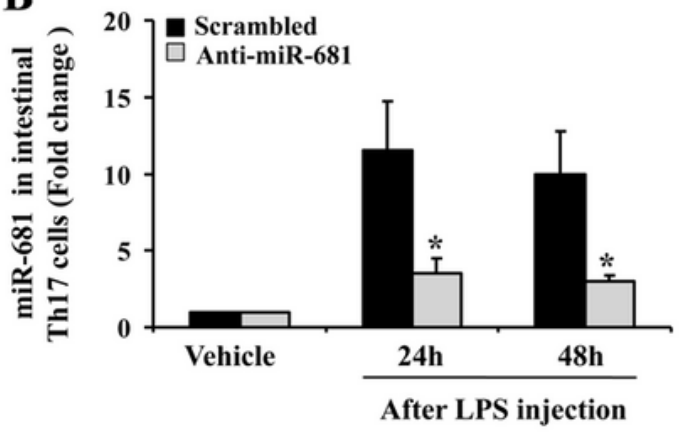

D

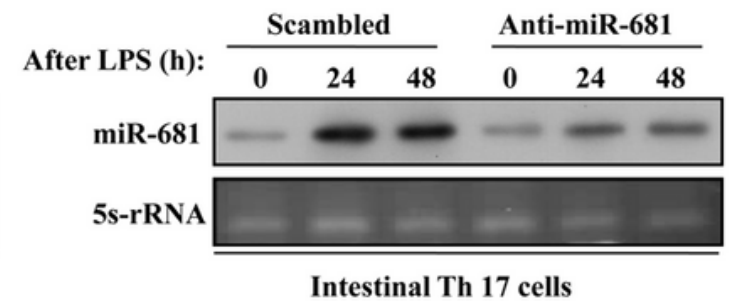

F
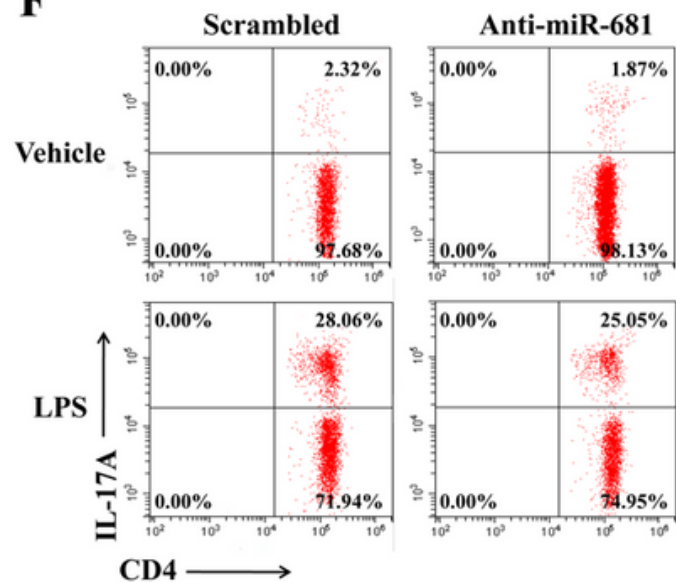

Th 17 cells in blood

H

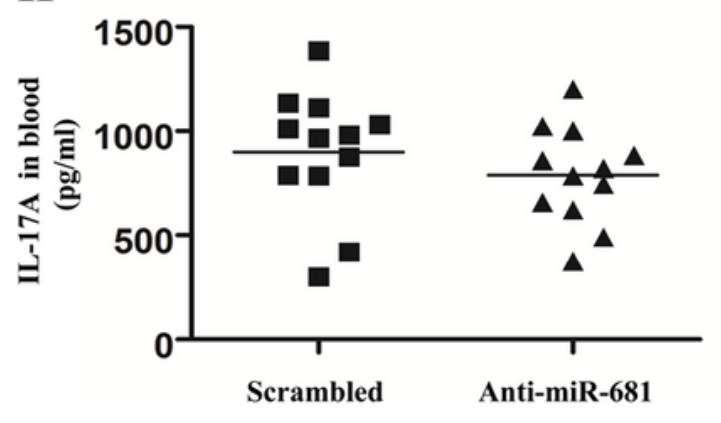

Figure 3 
Inhibition of miR-681 dramatically increases the number of intestinal Th17 cells during endotoxemia. A Quantitative PCR assessing miR-681 levels in circulating Th17 cells in endotoxemic mice injected with anti-miR-681 or scrambled control. ${ }^{*} \mathrm{P}<0.05$ vs. vehicle. B Quantitative PCR assessing miR-681 levels in intestinal Th17 cells in endotoxemia mice injected with anti-miR-681 or scrambled control. ${ }^{*} \mathrm{P}<0.05$ vs. vehicle. C Northern blot showing miR-681 expression in circulating Th17 cells isolated from endotoxemic mice after anti-miR-681 treatment. Forty micrograms of total RNA extracted from circulating Th17 cells was used for northern blot analysis. 5s rRNA was probed as a loading control. D Northern blot analysis of miR-681 expression in intestinal Th17 cells isolated from endotoxemic mice after anti-miR-681 treatment. Forty micrograms of total RNA extracted from intestinal Th17 cells was used for northern blot analysis. 5s rRNA was probed as a loading control. E Flow cytometry analysis of IL-17A expression (gated on CD4+ events) in cells from the small intestine. Numbers in quadrants indicate percent cells in each. F Flow cytometry analysis of IL-17A expression (gated on CD4+ events) in blood cells. Numbers in quadrants indicate percent cells in each. G Levels of IL-17A in the small intestine of endotoxemic mice. Data are presented as mean $\pm S D ; n=6$ in each group. ${ }^{*} P<0.05$ vs. 1 day. HPlasma levels of IL-17A in mice $72 \mathrm{~h}$ after LPS injection. Data are presented as mean $\pm S D ; n=6$ in each group.

A
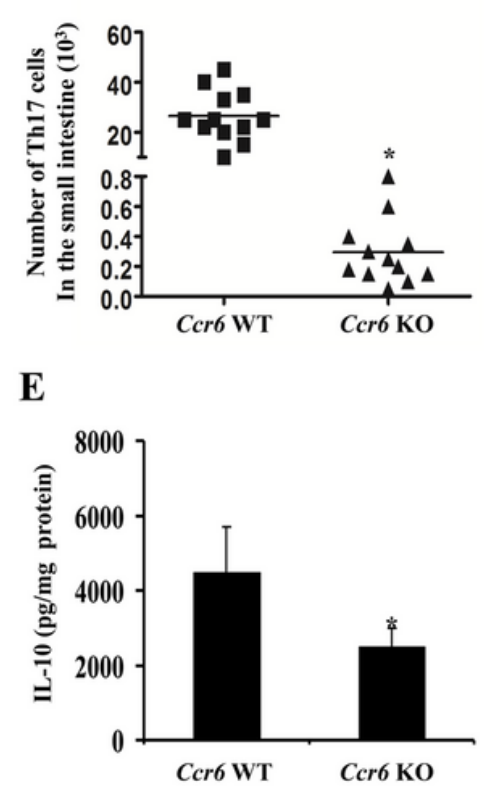

B

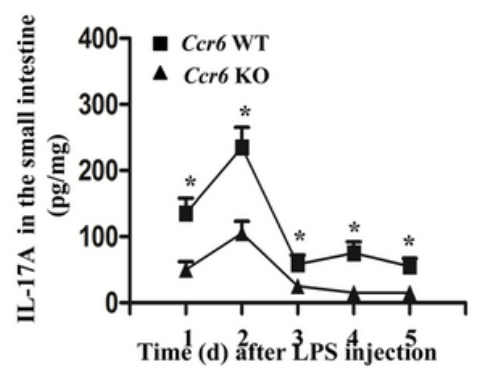

$\mathbf{F}$

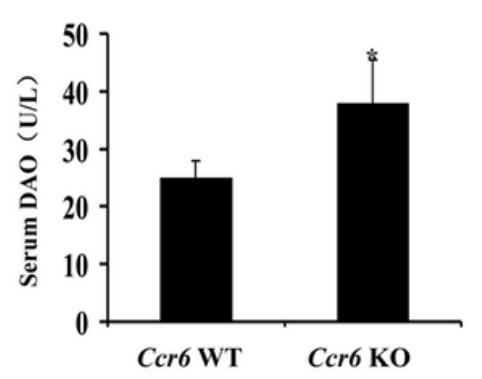

C

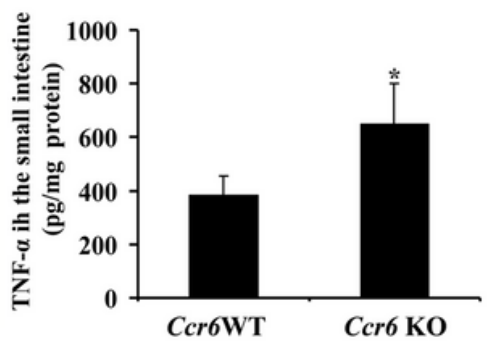

G

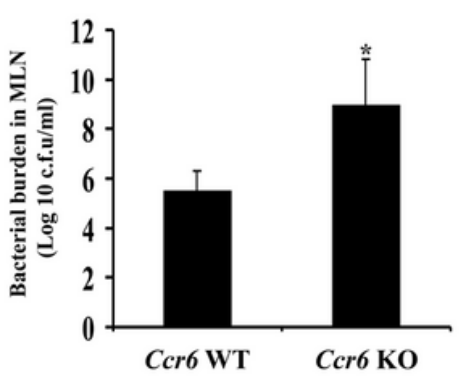

D

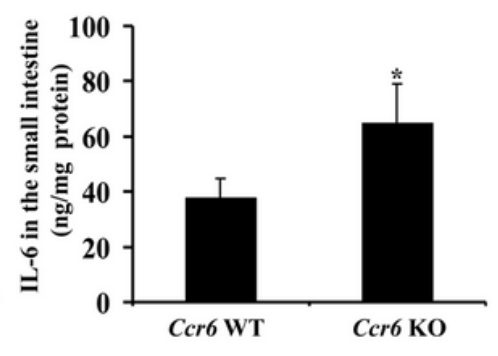

$\mathbf{H}$

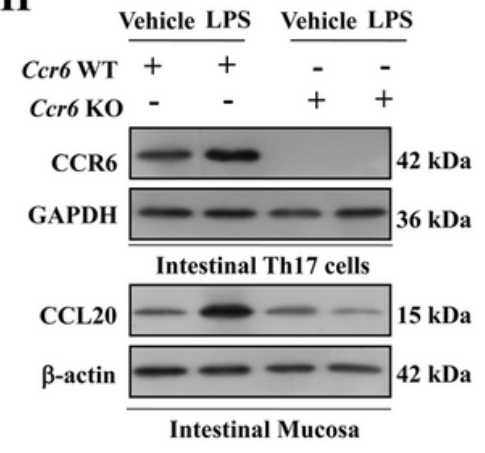

Figure 4

CCR6-mediated recruitment of intestinal Th17 cells to the intestine mitigates intestinal inflammation in endotoxemic mice. A Flow cytometry analysis of the number of Th17 cells in the small intestine isolated from CCR6 WT and KO mice $72 \mathrm{~h}$ after LPS treatment. ${ }^{*} \mathrm{P}<0.05 \mathrm{vs}$. $0 \mathrm{~h}$. B Levels of IL-17A in the small intestine of mice after LPS treatment. Data are presented as mean $\pm S D ; n=4$ in each group. ${ }^{*}<0.05$ vs. WT. C TNF-a concentration in the small intestine of CCR6 WT and KO mice $72 \mathrm{~h}$ after LPS treatment, as determined by ELISA. Data are presented as mean $\pm S D ; n=6$ in each group. ${ }^{*} P<0.05$ vs. WT. DIL- 6 concentrations in the small intestine of CCR6 WT and KO mice $72 \mathrm{~h}$ after LPS treatment, as determined by ELISA. Data are presented as mean \pm SD; $n=6$ in each group. ${ }^{*} P<0.01$ vs. WT. E IL-10 concentrations 
in the small intestine of CCR6 WT and KO mice $72 \mathrm{~h}$ after LPS treatment, as determined by ELISA. Data are presented as mean $\pm S D ; n=6$ in each group. ${ }^{*} P<0.01$ vs. WT. F SerumDAO concentration in mice 72 $\mathrm{h}$ after LPS treatment, as determined by ELISA. Data are presented as mean $\pm S D ; n=6$ in each group. ${ }^{*} P$ $<0.05$ versus WT. G Bacterial burden in MLNs collected from mice $72 \mathrm{~h}$ after LPS treatment. ${ }^{*} \mathrm{P}<0.01$ vs. WT. H Western blot showing CCR6 protein levels in intestinal Th17 cells and CCL20 protein levels in the intestinal mucosa. $\beta$-actin and GAPDH was used as a loading control.

A

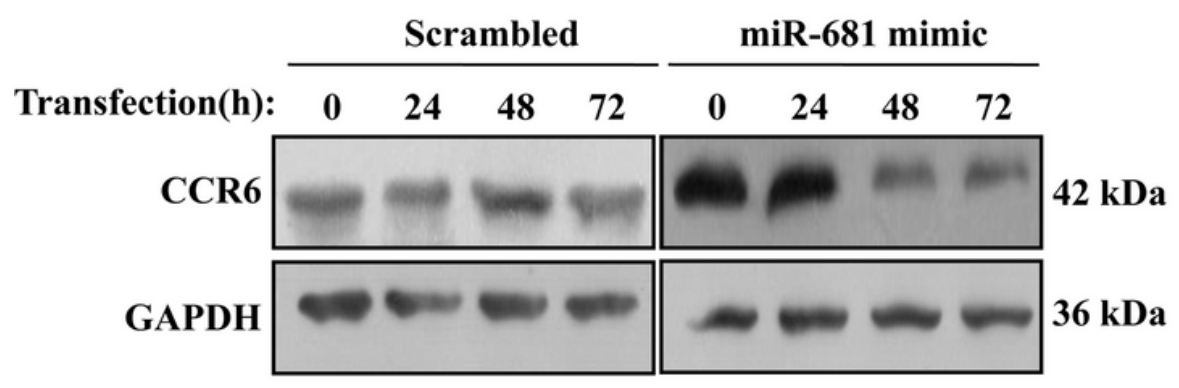

C

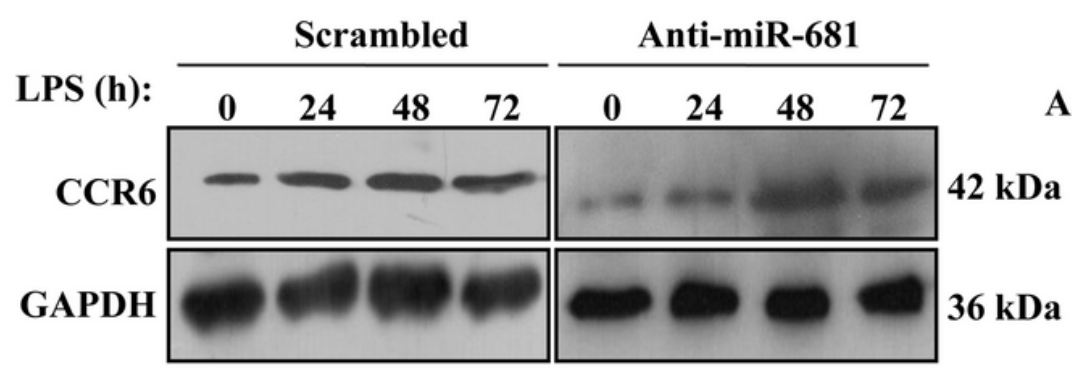

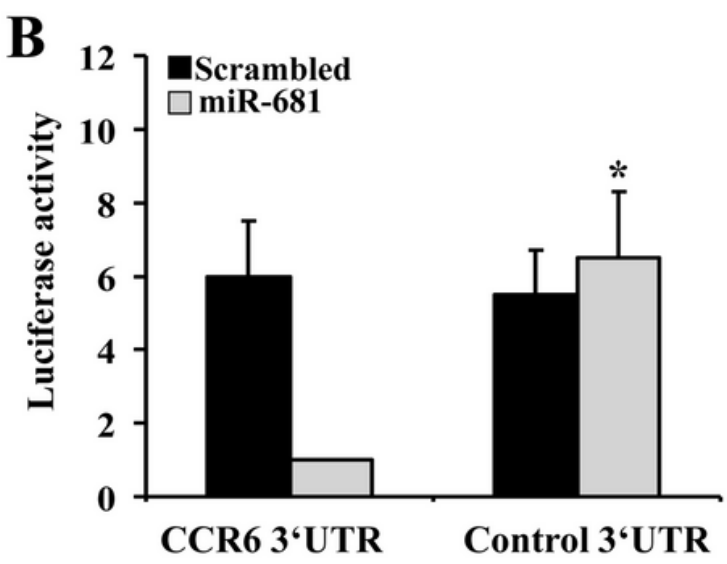

D

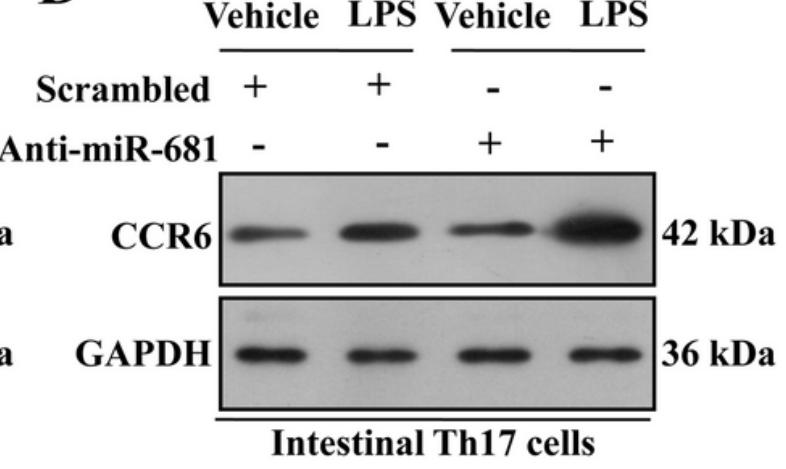

Figure 5

miR-681 directly suppresses CCR6 expression during LPS stimulation. A CD4+T cells were transfected with miR-681 mimic or scrambled control, followed by western blot analysis using whole cell lysates collected at different time points. B Luciferase reporter assay was conducted using constructs carrying the CCR6 3'UTR or an antisense control sequence. HEK293 cells were co-transfected with these constructs along with the miR-681 mimic or scrambled control. ${ }^{*} P<0.05$ vs. CCR63'UTR treated with miR681. C CD4+T cells transfected with anti-miR-681 LNA or scrambled LNA control were treated with LPS, and whole-cell lysates collected at the indicated time points were used for western blot analysis. $D$ Western blot showing the CCR6 protein levels in intestinal Th17 cells isolated from mice $72 \mathrm{~h}$ after LPS injection. GAPDH was used as a loading control. 
A
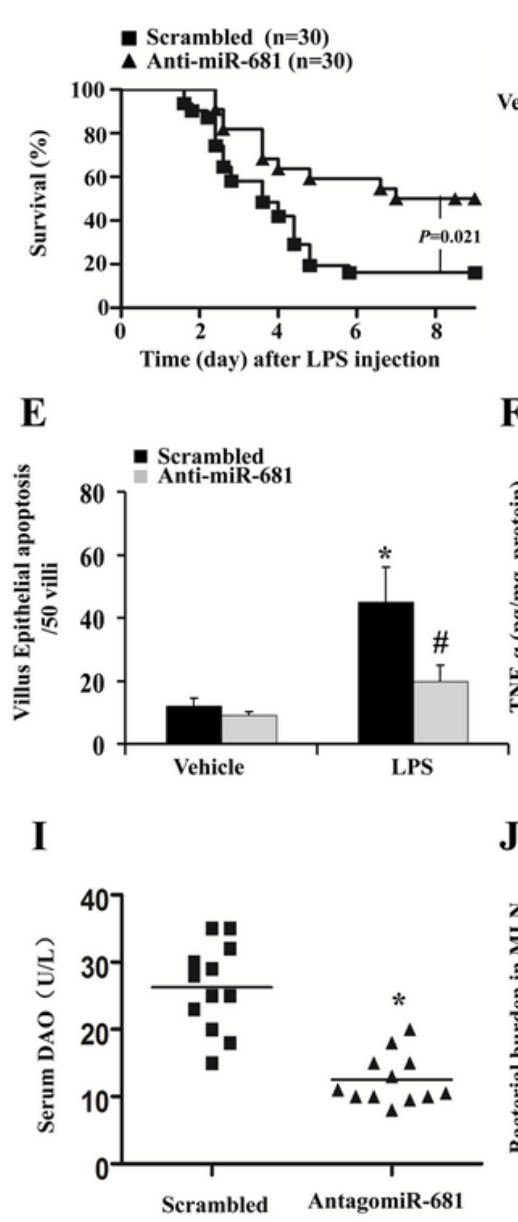

B

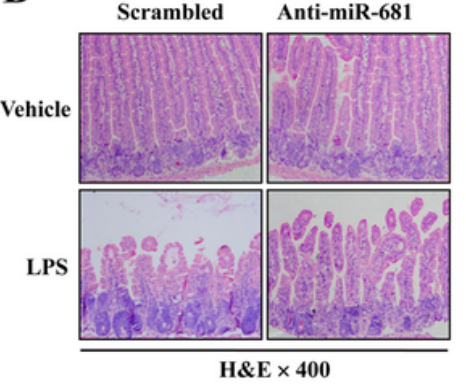

F

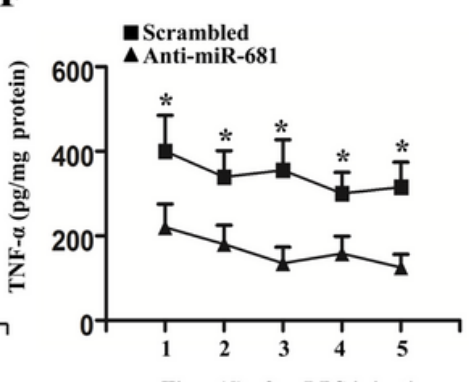

J

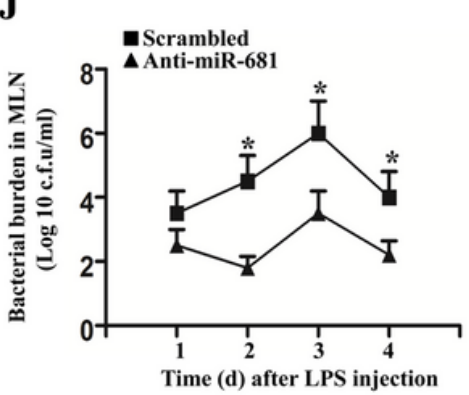

C

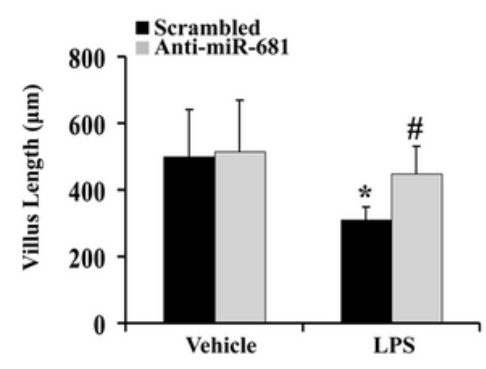

G

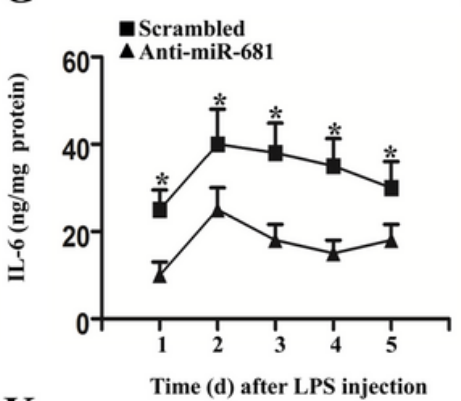

K

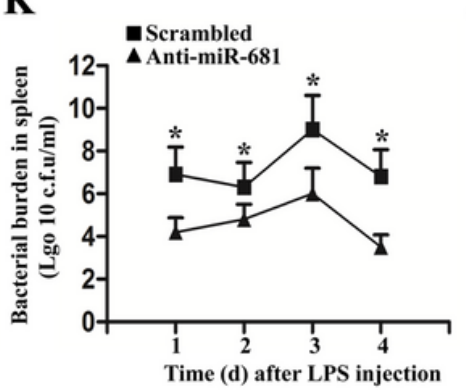

D

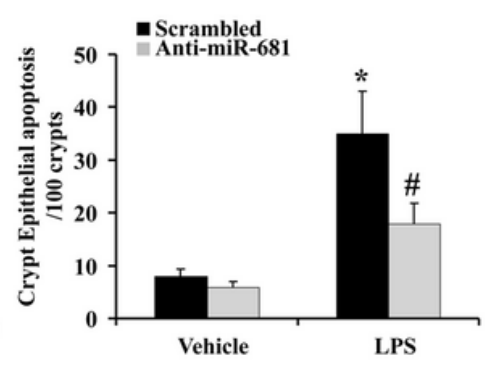

H

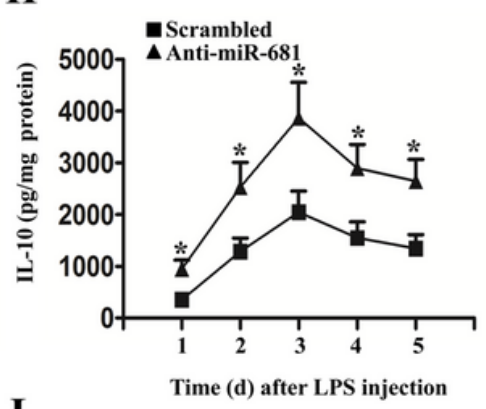

L

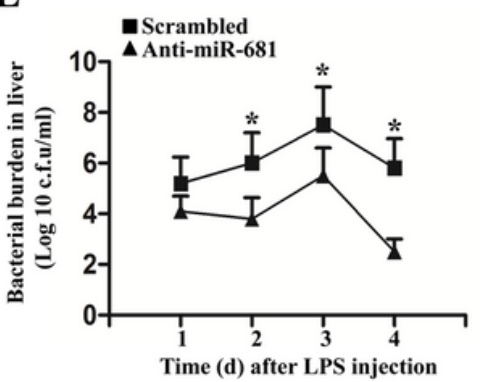

Figure 6

Anti-miR-681 mitigates endotoxemia-induced intestinal injury. A Survival of mice injected with LPS. BH\&E staining of jejunum sections, at $\times 400$ magnification. $C$ Villus length was quantified in sections of jejunum collected $72 \mathrm{~h}$ after LPS injection. Data are presented as mean $\pm S D ; n=6$ in each group. ${ }^{*} P<0.05$ vs. vehicle; \#P $<0.01$ vs. scrambled. D Apoptosis in intact crypts $72 \mathrm{~h}$ after LPS injection was analyzed by TUNEL staining. The intact crypt was defined as full longitudinal sections of crypts containing at least 14 cells, including at least one Paneth cells. Data are presented as mean $\pm S D ; n=6$ in each group. ${ }^{*} P<0.05$ vs. vehicle; $\# \mathrm{P}<0.05$ vs. scrambled. E Apoptosis in the intestinal epithelium of villi $72 \mathrm{~h}$ after LPS injection was analyzed by TUNEL staining. Data are presented as mean $\pm S D ; n=6$ in each group. * $P$ $<0.01$ vs. vehicle; $\# P<0.01$ vs. scrambled. F TNF-a concentration in the small intestine, as determined by ELISA. Data are presented as mean $\pm S D ; n=4$ in each group. ${ }^{*} P<0.05$ vs. scrambled. G IL- 6 concentration in the small intestine, as determined by ELISA. Data are presented as mean $\pm S D ; n=4$ in each group. * $\mathrm{P}<0.05$ vs. scrambled. H IL-10 concentration in the small intestine, as determined by ELISA. Data are presented as mean $\pm S D ; n=4$ in each group. ${ }^{*} P<0.01$ vs. scrambled. I SerumDAO concentration in mice $72 \mathrm{~h}$ after LPS treatment, as determined by ELISA. Data are presented as mean \pm $\mathrm{SD} ; \mathrm{n}=4$ in each group. $\mathrm{J}$ Bacterial burden in MLNs collected $24 \mathrm{~h}$ after LPS treatment, as determined by ELISA. Data are presented as mean $\pm S D ; n=4$ in each group. ${ }^{*} P<0.05$ vs. scrambled. $K$ Bacterial burden in spleens collected $24 \mathrm{~h}$ after LPS treatment, as determined by ELISA. Data are presented as mean \pm SD; 
$\mathrm{n}=4$ in each group. * $\mathrm{P}<0.01$ vs. scrambled. L Bacterial burden in livers collected $24 \mathrm{~h}$ after LPS treatment, as determined by ELISA. Data are presented as mean $\pm S D ; n=4$ in each group. * $P<0.05$ vs. scrambled.
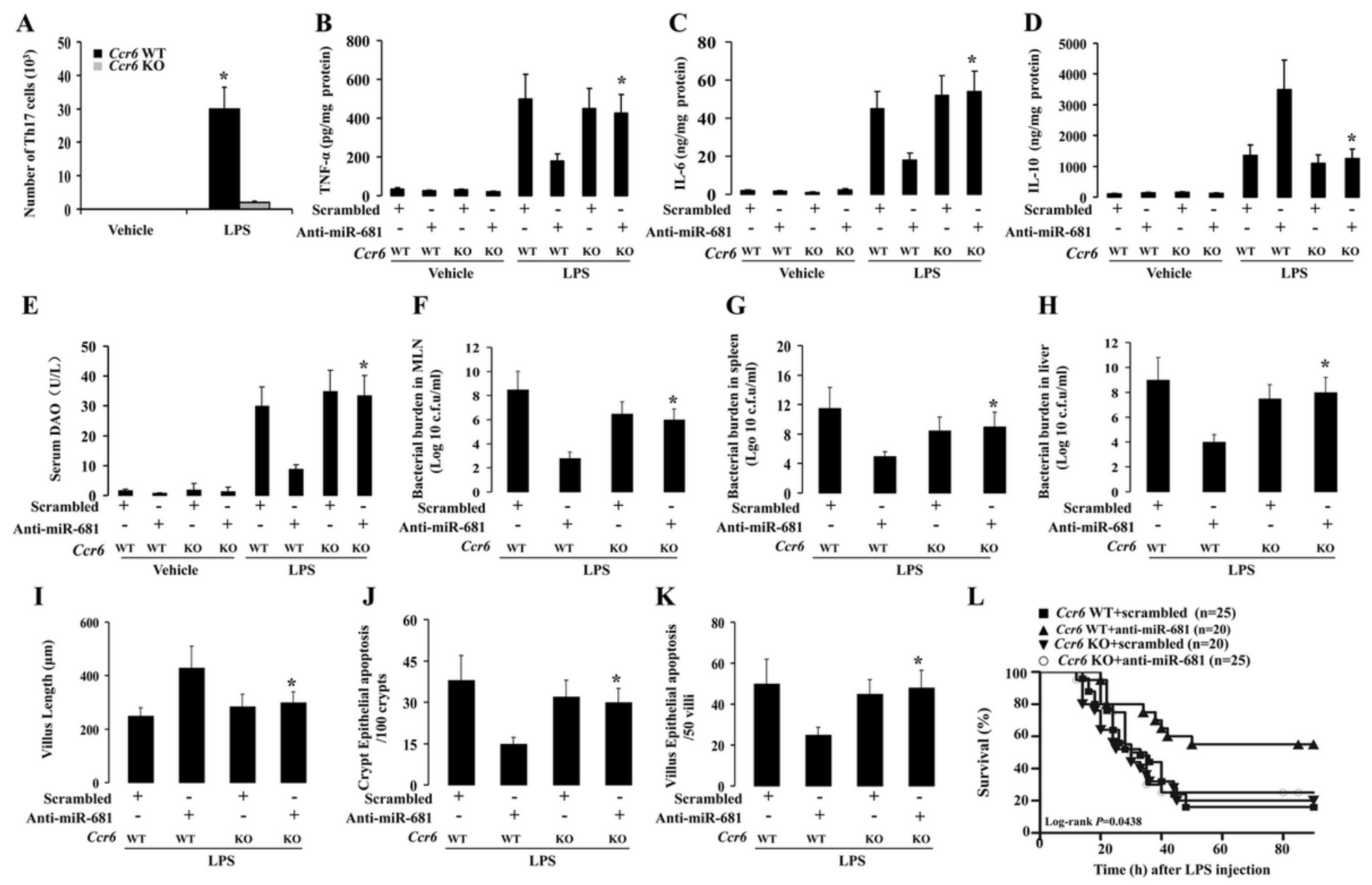

Figure 7

The protective effect of anti-miR-681 against endotoxemia-induced intestinal injury depends on CCR6mediated recruitment of Th17 cells to the intestine. A Th17 cell number in the jejunum. Data are presented as mean $\pm S D ; n=6$ in each group. ${ }^{*} P<0.05$ vs. KO in LPS group. B TNF-a concentration in the small intestine $72 \mathrm{~h}$ after LPS injection, as determined by ELISA. Data are presented as mean \pm SD; $\mathrm{n}=6$ in each group. *P < 0.01 vs. WT injected with anti-miR-681 in LPS group. C IL-6 concentration in the small intestine $72 \mathrm{~h}$ after LPS injection, as determined by ELISA. Data are presented as mean \pm SD; $\mathrm{n}=6$ in each group. ${ }^{*} \mathrm{P}<0.05$ vs. WT injected with anti-miR-681 in LPS group. D IL-10 concentration in the small intestine $72 \mathrm{~h}$ after LPS injection, as determined by ELISA. Data are presented as mean $\pm S D ; n=6$ in each group. ${ }^{*} \mathrm{P}<0.01$ vs. WT injected with anti-miR-681 in LPS group. E Serum DAO concentration in mice $72 \mathrm{~h}$ after LPS treatment, as determined by ELISA. Data are presented as mean \pm SD; $\mathrm{n}=6 \mathrm{in}$ each group. *P $<0.05$ vs. WT injected with anti-miR-681 in LPS group. F Bacterial load in MLNs collected $24 \mathrm{~h}$ after LPS treatment, as determined by ELISA. Data are presented as mean \pm SD; $n=4$ in each group. *P < 0.05 vs. WT injected with anti-miR-681. G Bacterial load in spleens collected $24 \mathrm{~h}$ after LPS treatment, as determined by ELISA. Data are presented as mean \pm SD; $n=4$ in each group. * $P<0.05$ vs. WT injected 
with anti-miR-681. H Bacterial load in livers collected $24 \mathrm{~h}$ after LPS treatment, as determined by ELISA. Data are presented as mean $\pm S D ; n=4$ in each group. ${ }^{*} P<0.01$ vs. WT injected with anti-miR-681. I Villus length was quantified in sections of jejunum collected $72 \mathrm{~h}$ after LPS injection. Data are presented as mean $\pm S D ; n=6$ in each group. ${ }^{*} P<0.05$ vs. WT injected with anti-miR-681. J Apoptosis in intact crypts $72 \mathrm{~h}$ after LPS injection was analyzed by TUNEL staining (brown). Data are presented as mean \pm $S D ; n=6$ in each group. ${ }^{*} P<0.05$ vs. WT injected with anti-miR-681. K Apoptosis in villus epithelium $72 \mathrm{~h}$ after LPS injection was analyzed by TUNEL staining (brown). Data are presented as mean $\pm S D ; n=6$ in each group. ${ }^{*} P<0.05$ vs. WT injected with anti-miR-681. L Survival of mice subjected to LPS injection.

\section{Supplementary Files}

This is a list of supplementary files associated with this preprint. Click to download.

- SupplFigure1.tif 